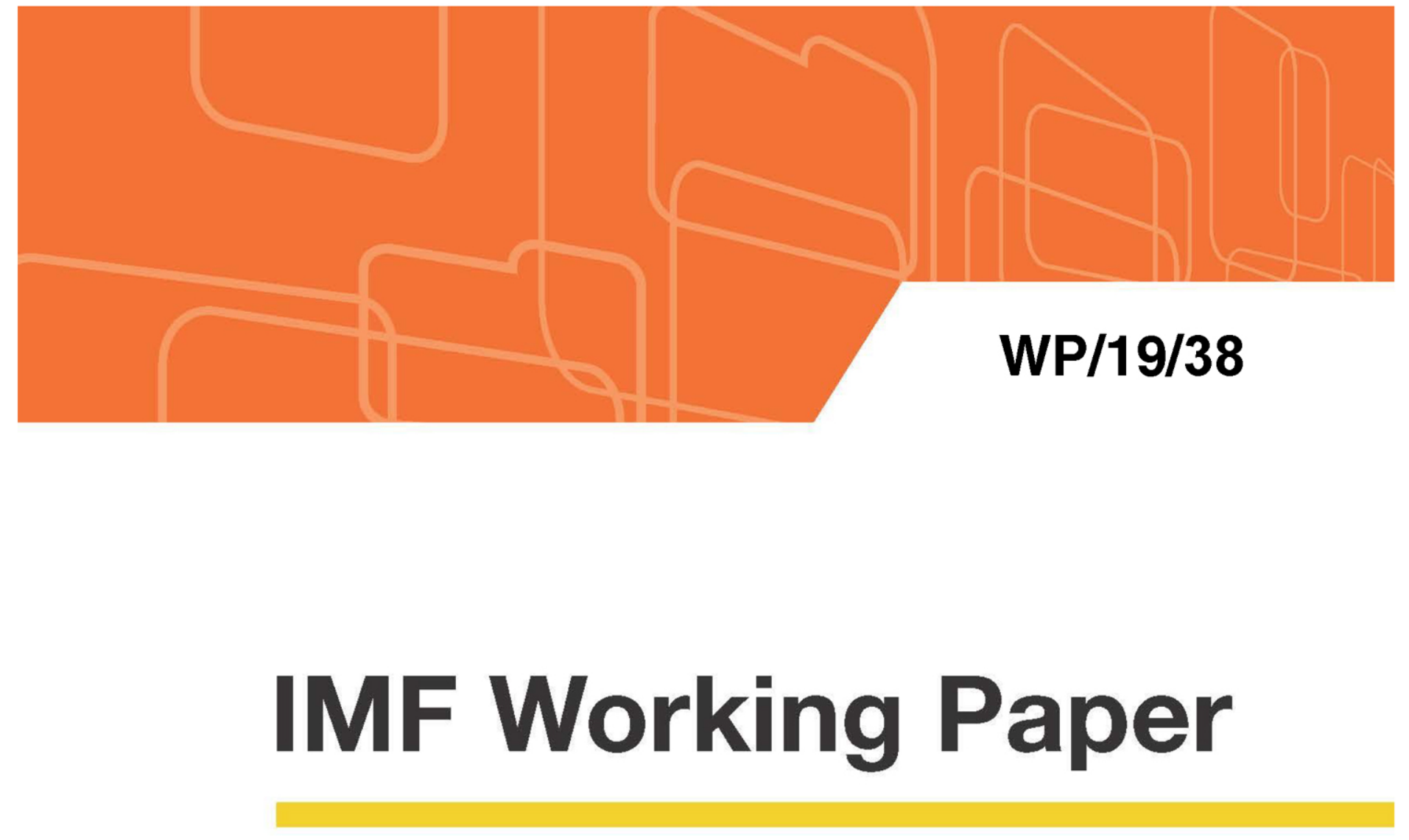

\title{
The Impact of Community Based Health Insurance Schemes on Out-of-Pocket Healthcare Spending: Evidence from Rwanda
}

by Andinet Woldemichael, Daniel Gurara, Abebe Shimeles

IMF Working Papers describe research in progress by the author(s) and are published to elicit comments and to encourage debate. The views expressed in IMF Working Papers are those of the author(s) and do not necessarily represent the views of the IMF, its Executive Board, or IMF management. 


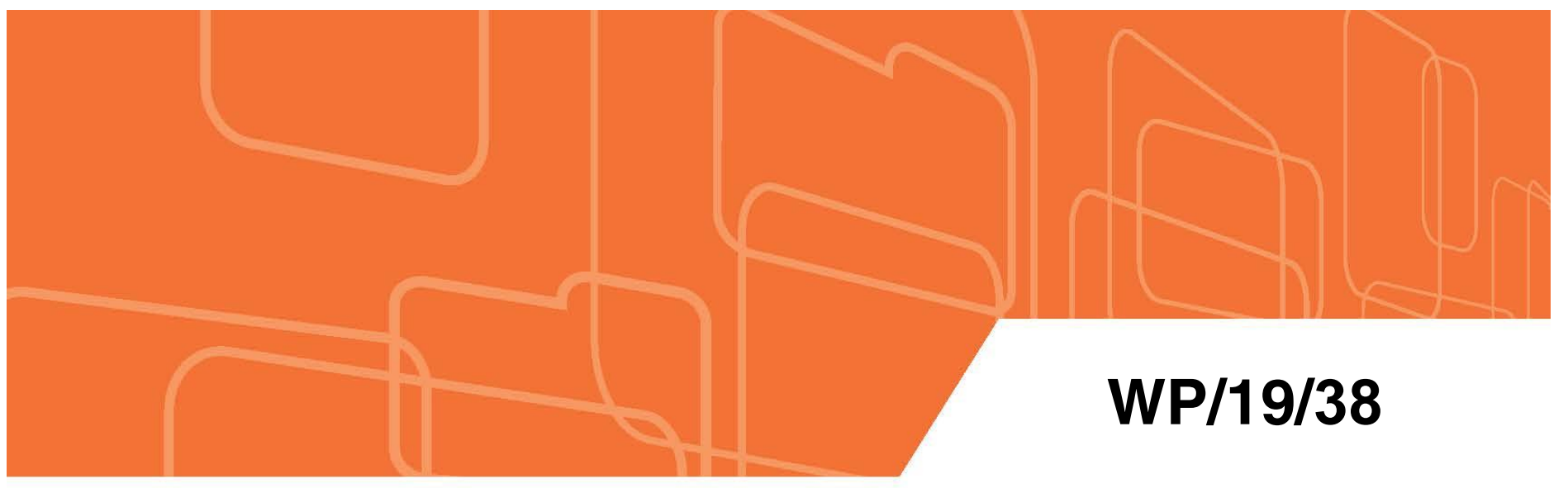

\section{IMF Working Paper}

\section{The Impact of Community Based Health Insurance Schemes on Out-of-Pocket Healthcare Spending: Evidence from Rwanda}

by Andinet Woldemichael, Daniel Gurara, Abebe Shimeles

IMF Working Papers describe research in progress by the author(s) and are published to elicit comments and to encourage debate. The views expressed in IMF Working Papers are those of the author(s) and do not necessarily represent the views of the IMF, its Executive Board, or IMF management. 


\title{
IMF Working Paper
}

Strategy, Policy and Review Department

\section{The Impact of Community Based Health Insurance Schemes on Out-of-Pocket Healthcare Spending: Evidence from Rwanda ${ }^{1}$}

\section{Prepared by Andinet Woldemichael, Daniel Gurara, and Abebe Shimeles}

Authorized for distribution by Ali Mansoor

February 2019

IMF Working Papers describe research in progress by the author(s) and are published to elicit comments and to encourage debate. The views expressed in IMF Working Papers are those of the author(s) and do not necessarily represent the views of the IMF, its Executive Board, or IMF management.

\begin{abstract}
Achieving universal health coverage, including financial risk protection and access to quality essential health-care services, is one of the main Sustainable Development Goals. In low-income countries, innovative and affordable health financing systems are key to realize these goals. This paper assesses the impacts of Community-Based Health Insurance Scheme in Rwanda on health-related financial risks using a nationally representative household survey data collected over a ten-year period. We find that the scheme significantly reduce annual per capita out-of-pocket spending by about 3,600 Rwandan Franc (about US\$12) or about 83 percent of average per capita healthcare expenditure compared to the baseline level in 2000. The impacts however favor the rich as compared to the poor. The program also reduces the incidence of catastrophic healthcare spending significantly.
\end{abstract}

JEL Classification Numbers: C21, C34, D04, I13, I15

Keywords: Healthcare spending, health insurance, low-income, Rwanda

Authors’ E-Mail Addresses: a.woldemichael@afdb.org; dgurara@imf.org; a.shimeles@afdb.org

\footnotetext{
${ }^{1}$ We thank Claudia Berg, Baoping Shang, and Mouhamadou Sy for their helpful comments.
} 


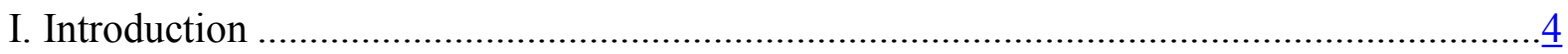

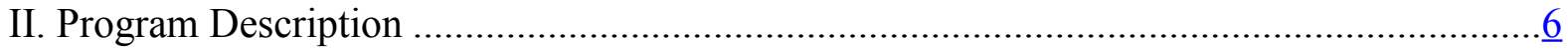

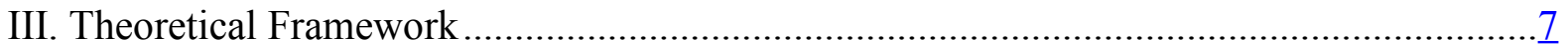

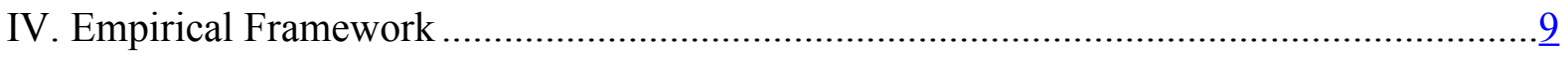

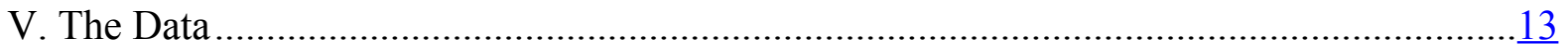

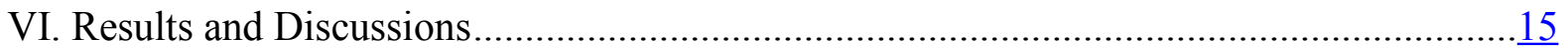

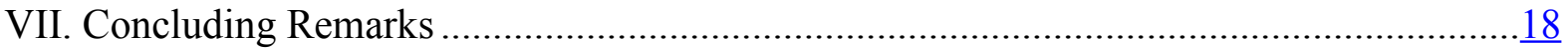

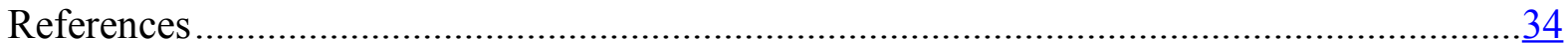

\section{Figures}

1. Histogram of Log of Out-of-Pocket Healthcare Spending on Overall, Outpatient,

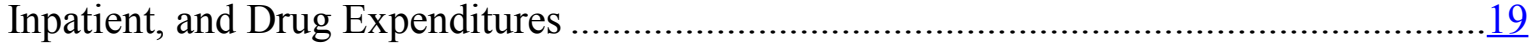

2. Kernel Density of Treatment Effects .........................................................................20

3. ATE on Overall Out-Of-Pocket Expenditure by Age, Income, and Wealth Percentiles......21

4. ATE on Outpatient Expenditure by Age, Income and Wealth Percentiles........................21

5. ATE on Inpatient Expenditure by Age, Income, and Wealth Percentiles .........................22

6. ATE on Drug Expenditure by Age, Income, and Wealth Percentiles ..............................22

\section{Tables}

1. Health Insurance Status........................................................................................23

2. Per Capita Out-of-Pocket Healthcare Spending (RWF) in 2000 Prices ...........................23

3. Descriptive Statistics of Control Variables................................................................. 24

4. Overall Healthcare Expenditure: ETPM Posterior Means and Standard Deviation .............25

5. Outpatient Expenditure: ETPM Posterior Means and Standard Deviations ........................ $\underline{26}$

6. Inpatient Expenditure: ETPM Posterior Means and Standard Deviations..........................27

7. Drug Expenditure: ETPM Posterior Means and Standard Deviations...............................28

8. Overall Healthcare Expenditure Net of Premium: ETPM Posterior Means and

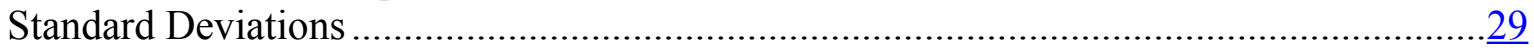

9. Average Treatment Effects on the Probability and the Amount of Healthcare

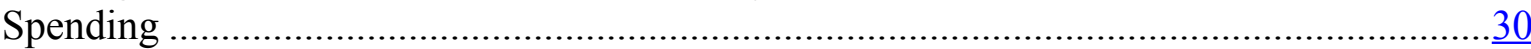

10. Sensitivity Analysis I: Sensitivity to Different Prior Selections .....................................

\section{Appendices}

A. Estimation Algorithm of Two-Part Model with Binary Selection ................................ $\underline{31}$

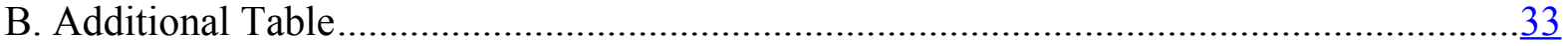




\section{INTRODUCTION}

Adverse health shocks are frequent events in low-income countries, posing one of the biggest threats to the lives and livelihoods of the poor. In addition to physical suffering from illnesses, households face significant financial risk of paying large medical bills. In low-income countries, third party payers and prepayment systems — such as health insurance and tax-based schemesare not widely available to protect households from health-related financial risks. The common coping mechanisms to deal with large out-of-pocket medical bills are through intertemporal transfers (saving, borrowing, or selling assets), reducing current consumption levels, or forgoing medical care because of affordability (O’Donnell and Wagstaff, 2008). For instance, in Africa, out of pocket spending accounts for 50 percent of the total healthcare expenditure while 30 percent of households cope through borrowing and selling assets (Leive and $\mathrm{Xu}, 2008$ ). The coping mechanisms, however, has detrimental impact on welfare and in many cases are catastrophic, driving households into poverty (Wagstaff and others, 2011; Leive and Xu, 2008).

Due to their advantages over standard health insurance products, Community Based Health Insurance (CBHI) schemes are considered better alternatives to fill the void in the healthcare financing system of many low- and middle-income countries (Jutting, 2004). The overarching goals of these programs are increasing access to healthcare services, protecting households from health-related financial risks, and ultimately improving health status of the poor. In recent years, governments are rolling out CBHI schemes at the national level, integrating them into the existing healthcare provision and financing systems, and allocating significant resources in the form of subsidies and steering operational activities. The proliferation of CBHI schemes in many low-income countries as mainstream healthcare financing mechanisms has triggered considerable analytical and policy questions concerning their impact in providing access to healthcare services and protecting households from financial risks due to illnesses.

Rwanda is one of the few African countries to implement the CBHI program as integral part of its national healthcare financing system and provide health insurance coverage for the majority of its population. The country started to implement the program, locally referred to as Mutuelle de santé, in 2004 and covered about 86 percent of the population in 2008 (MoH, 2010). Empirical studies find that the Rwanda CBHI program has significantly increased outpatient utilization rates. However, there are some concerns that the subsidized flat premium of about U\$2 per person is still too high for the poor, especially for families of larger sizes (Shimeles, 2010; Lu and others, 2012; Woldemichael and Shimeles, 2015). With additional expenses for transportation and nonessential drugs that are not covered by the insurance scheme, there is a debate that the insurance scheme could increase out-of-pocket cost, especially for the poor. This paper investigates the causal effects of CBHI program on out-of-pocket healthcare spending in Rwanda.

We use three rounds of nationally representative household survey data from the Rwandan Integrated Household Living Conditions Survey conducted in 2000, 2005, and 2010. We guide our empirical analysis using a simple model of demand for health and health insurance. The 
major empirical issues we encounter in estimating the effect of CBHI on out-of-pocket spending are non-normal expenditure distribution and endogeneity in $\mathrm{CBHI}$ enrollment. Non-normality arises mainly due to high proportion of zeros and heteroskedasticity in healthcare expenditure. We observe zeros in healthcare expenditure either due to "corner solutions" in the choice problem or modern "health care goods and services" are not in individuals' choice set. Either way, high proportion of zeros poses discontinuity in the distribution of expenditure that needs to be addressed (Trivedi, 2002). The second problem is endogeneity, arising from self-selection into or out of CBHI schemes. Insured and uninsured individuals may exhibit behavioral differences that may be correlated with spending behavior because of, for instance, underlying health conditions, health behavior, or risk aversion.

We address these important empirical issues using Extended Two-Part Model (ETPM) proposed by Deb, Munkin, and Trivedi (2006). In the model, the decision to enroll in CBHI schemes, the decision to spend, and the conditional amount of spending are simultaneously modeled in a three-equation system. In addition, estimates from the Two-Part Models (TPM) in general and the ETPM in particular provide useful economic interpretation in which the first part is the probability of an "interior solution" to the choice problem, and the second part is the level of consumption conditional on an "interior solution" (Trivedi, 2002). The model is estimated using Bayesian methods with Markov Chain Monte Carlo (MCMC) simulation techniques.

The evidence on the impact of CBHI schemes on out-of-pocket healthcare spending is mixed and vary from country to country. For instance, while the New Cooperative Medical Scheme (NCMS) in China have no impact in reducing out-of-pocket spending and even slightly increases financial risks (Wagstaff and others, 2009; Wagstaff and Lindelow, 2008), the New Rural Cooperative Medical Schemes (RCMS) have some success in reducing out-of-pocket and the incidence of catastrophic spending (Wagstaff and Yu, 2007; Yip and Hsiao, 2009). Similarly, findings from Vietnam (Wagstaff, 2007; Sepehri and others, 2006) and Mexico (Galarraga and others, 2010; King and others, 2009) are mixed but show some success in reducing the incidence of catastrophic and out-of-pocket spending. Studies from Africa, such as Egypt's School Health Insurance program and Ghana's National Health Insurance Program, find evidence of reduction in out-of-pocket and catastrophic spending (Yip and Berman, 2001; Nguyen, Rajkotia, and Wang, 2011). ${ }^{2}$

\footnotetext{
${ }^{2}$ Despite the popularity of CBHI schemes, there is noticeable evidence gap on the impact of CBHI schemes on out-of-pocket healthcare spending in the African context. For instance, out of the 18 studies systematically reviewed in Acharya (2012), only two are from Africa, Burkina Faso (Gnawali and others, 2009) and Ghana (Mensah, Oppong, and Schmidt, 2010), and their focus is primarily on healthcare utilization outcomes. Recent studies include Shimeles (2010) and Lu and others (2013) from Rwanda which investigate the impact of CBHI schemes on utilization and the incidence of "catastrophic" spending. Similarly, Merbratie and others (2013) and Yilma and others (2015) investigate the impact of pilot CBHI program in Ethiopia on utilization, consumption and borrowing habits to finance out-of-pocket healthcare spending.
} 
Comprehensive and systematic review of the literature on CBHI has been done by Ekman (2004), Geidion, Andrés, and Díaz (2012), Acharya and others (2010), and Escobar, Griffin, and Shaw (2010). The consensus in the literature is that there is considerable heterogeneity in the impact of CBHI on various outcomes depending on country settings, program implementation, scheme design, and so on. However, although the literature is voluminous, few studies establish causality from which meaningful policy recommendations can be drawn (see for instance, Lu and others, 2013; Merbratie and others, 2013; Yilma and others, 2015). In addition, the focus is mainly on the incidence of financial risks (incidence of out-of-pocket or catastrophic expenditure) ignoring the magnitude (depth) of the monetary impact such as the amount of out-of-pocket spending. This paper fills these gaps.

Our paper contributes to the existing literature by examining the impact of CBHI on the incidence and the amount of out-of-pocket healthcare expenditure. The findings show that the effect of CBHI on out-of-pocket spending is non-linear. It increases the probability of spending by 32 percentage points - reflecting increased utilization rates - but decreases the amount of total out-of-pocket expenditure by about RWF3,600 (approximately US\$12 in 2000 prices and exchange rate). This reduction represents about 83 percent of the average per capita healthcare expenditure in 2000 prices. Regarding spending on specific healthcare services, the results are mixed. While the scheme significantly decreases the amount of expenditure on drug, it increases the probability and the amount of spending on outpatient services highlighting higher utilization rates of consultation, medical examination, and laboratory services. However, we do not detect any impact on inpatient spending. There is also evidence of heterogeneity in treatment effects across income and wealth distributions. Contrary to the government's aim of making CBHI schemes accessible and affordable by the poor by subsidizing premiums, the magnitude of the impacts in terms of reducing out-ofpocket expenditure are higher for the richer households. This is in line with previous findings that the CBHI do no favor the poor in the relative reduction in out-of-pocket expenditure (Umeh and Feeley, 2017; Schneider and Diop, 2001) In general, the results are robust to different model specifications and, not surprisingly, present overwhelming evidence of selection on observed and unobserved factors.

The rest of the paper is organized as follows. Section two describes the CBHI program in Rwanda. Section three and four discuss the theoretical and empirical frameworks, respectively. Section five presents the data, followed by discussions on the results in section six. The last section concludes the paper.

\section{Program Description}

The Rwandan CBHI (Mutuelle) program was first introduced in 1999 as a pilot project in three districts (Byumba, Kabgayi, and Kabutari). Following the approval of the Mutuelle Health Insurance Policy by the government in 2004, the country formally implemented the program as integral part of its healthcare financing system. There have been numerous amendments and policy changes on the design, organizational structure, benefit packages, 
premiums schedules, co-pays, and other features of the program. The CBHI schemes are instituted as health insurance organizations based on a partnership between the community and healthcare providers (Diop, Butera, and Damascene, 2005). In line with the government's fiscal, administrative and political decentralization strategies, the schemes are managed at the district level in a decentralized manner. Each district has its own designated staff in charge of enrollment drives, collection of insurance premiums, and billing processes for services provided at the health center, management of the mutual health insurance fund ("Fonds Mutuelle de Sante"), and so on. Management and operational activities are performed at the district level, which has a director and an auditor appointed by the Ministry of Health. In addition, elected community mobilization committees actively engage at village and cell levels serving for a two-year term $(\mathrm{MoH}, 2010)$.

Participation in the Rwandan CBHI schemes is voluntary. Prior to 2007, enrollment was on a household basis where a household with up to seven family members pay premiums ranging between RWF2,500 to RWF11,000 per year and co-pays of up to RWF150 for services provided at health clinics and up to 50 percent of the cost at hospitals ( $\mathrm{Lu}$ and others, 2012; Diop, Butera, and Damascene, 2005). Since 2007, however, enrollment has been on individual basis with each member paying a flat rate of RWF1,000 per year and co-pays of RWF200 at clinics and 10 percent at hospitals. The CBHI program is highly subsidized where revenues from premium collection cover only 50 percent of the fund and the rest comes from designated government fund, other public insurance systems (Medical \& Health Insurance La Rwandaise d'Assurance Maladie (RAMA)), charitable organizations, NGOs, and development partners (Lu and others, 2012).

The benefit packages include comprehensive preventive and curative services and essential drugs provided at the health centers and some referral services at hospitals. After 2006, the national health insurance policy was amended to ensure members have access to a minimum service package (minimum package of activities (MPA)) at the health centers and complementary service package (Complementary Package of Activities (CPA)) at hospitals. While the MPA covers promotional, preventive, and curative services that could be provided at the health clinic level, the CPA includes services provided at hospitals including minor surgeries. The health centers also serve as gatekeepers to discourage moral hazard at the hospitals (Schneider and Diop, 2001).

\section{THEORETICAL FRAMEWORK}

We present a simple theoretical framework of health investment and consumption with health insurance choices to guide our empirical analysis. It provides the basis for the empirical model which addresses self-selection in health insurance and heterogeneity that arises mainly from preferences, risk aversion, and other unobserved factors. The theoretical framework is based on Bolhaa, Lindeboom, and van der Klaauw (2008) and other studies such as Brown and Finkelstein (2008) and Bajari, Hong, and Khwaja (2010). 
Suppose that individual $i$ earns income $Y_{i}$, which can be spent on consumption $c_{i}$ and medical expenses $m_{i}$ such that $Y_{i}=c_{i}+m_{i}$. The household derives utility from consumption and health $h_{i}$ :

$$
U\left(c_{i}, h_{i}\right)=u\left(c_{i}\right)^{\alpha} h_{i}^{1-\alpha},
$$

where $\alpha$ is the relative preference for health and consumption. A higher $\alpha$ corresponds to lower preference for health. Similarly, utility from health and consumption depends on the degree of risk aversion in that risk averse individuals have preference to avoid consumption shocks and invest in health to reduce shocks. Assume that health investment, denoted by $V_{i}$, consists of purchase of healthcare and associated services such as transportation. In the presence of health insurance options such as CBHI, households medical spending can be given by $m_{i}=r I_{i}+p\left(I_{i}\right) V_{i}$, where $I_{i}$ denotes health insurance, $r$ denotes exogenously determined flat premium and $p\left(I_{i}\right)$ is the price of medical services.

Household's level of health depends not only on the volume of health investment, but also on existing health conditions denoted by $h_{i 0}$ and health shocks denoted by $\Delta_{i}$, that is,

$$
h_{i}=f\left(V_{i}, h_{i 0}, \Delta_{i}\right)
$$

where health increases with the volume of health investment $\left(f_{V}>0\right)$, decreases with increasing number of existing conditions and health shocks $\left(f_{\mu}<0\right.$ and $\left.f_{\Delta}<0\right)$. Let health shock takes the value 1 with $\lambda_{i}$ and 0 with probability $1-\lambda_{i}$. Then, household $i$ maximizes expected utility by choosing optimal levels of health insurance and volume of health investment. They choose optimal health insurance coverage before realization of shocks and choose optimal level of health investment after the realization of shocks. That is, individual $i$ makes optimal insurance choice by maximizing expected utility given by

$$
d_{i}=1\left[E\left[U\left(c_{i}, h_{i}\right) \mid I_{i}=1, h_{i 0}\right]>E\left[U\left(c_{i}, h_{i}\right) \mid I_{i}=0, h_{i 0}\right]\right]
$$

where $d_{i}=\{0,1\}$ and $1[\cdot]$ is indicator function taking the value 1 if the statement in the square bracket is true and zero, otherwise. Note that the optimal level of health insurance investment depends on the existing health conditions as well as preference parameters. Assuming constant relative risk aversion (CRRA) utility function $u\left(c_{i}\right)=\frac{c_{i}{ }^{1-\gamma}}{1-\gamma}$, households chose the optimal level of health investment by maximizing utility subject to the budget constraint and health function which gives us

$$
\frac{\partial U}{\partial V_{i}}=0: \quad \frac{c_{i}}{h_{i}}=\frac{\alpha(1-\gamma)}{(1-\alpha)} \frac{p\left(I_{i}\right)}{\frac{\partial f\left(V_{i}, h_{i 0}, \Delta_{i}\right)}{\partial V_{i}}}
$$

By substituting the expressions from the first order condition, we can obtain the optimal outof-pocket medical expenditure which can be given by 


$$
m_{i}\left(I_{i}^{*}, \mathrm{~V}_{i}^{*} ; Y_{i}, r, \gamma, \delta, \mu, \Delta\right)=r I^{*}+p\left(I^{*}\right) V^{*}=Y-\frac{\alpha(1-\gamma)}{(1-\alpha)} \frac{p\left(I^{*}\right) f\left(V^{*}, \mu, \Delta\right)}{f_{v}\left(V^{*}, \mu, \Delta\right)}
$$

The implication of equation (5) is that out-of-pocket spending depends on income, health insurance status, price of healthcare services, the level of health, returns to health investment, optimal volume of health investment, the relative weight of health in the utility function (1 $\alpha$ ), and the degree of risk aversion $(\gamma)$. It states that higher income, higher health status, higher weight on health investment $(1-\alpha)$ and lower risk preference $(\gamma)$ increases out-ofpocket healthcare spending. If the returns to health investment $\left(f_{v}\left(V^{*}, \mu, \Delta\right)=0\right)$ and the weight on consumption $(\alpha)$ are closer to zero, the model predicts zero out-of-pocket expenditure.

The theoretical framework also highlights self-selection in the uptake of health insurance. Factors such as existing health conditions, preference towards health, and risk aversion, which are unobserved, appear in both optimal health insurance choice and optimal out-of-pocket healthcare spending. It also points to the presence of greater heterogeneity in out-of-pocket spending due to differences in observed characteristics such as incomes and unobserved factors such as preference towards risk, the relative weight on health, and so on. As described next, our empirical strategy captures key predictions of the theoretical model. We start by jointly estimating the decision to enroll in CBHI schemes and out-of-pocket healthcare spending. Consistent with the prediction of the theoretical model, compared to the uninsured, we expect to find higher utilization of healthcare services and lower out of pocket expenditure by the insured households.

\section{EMPIRICAL FRAMEWORK}

This section lays out the empirical strategies to tackle three important issues: selection bias, censoring, and identification. To address endogeneity and censoring, we implement the ETPM proposed by Deb, Munkin, and Trivedi (2006). The standard TPM was first introduced by Cragg (1971) and popularized by the RAND health insurance experiment researchers in the 1980s to model healthcare expenditure data (Manning, Morris, and Newhouse (1981) and Manning, Duan, and Rogers (1987)). Unlike Tobit model, another commonly used method to model censored data, TPM is robust to high proportion of zeros

and heteroskedasticity with positive skewedness and high kurtosis. In addition, the sequential decisions on whether to spend and on how much to spend are modeled separately.

Endogeneity in health insurance choices arises because individuals self-select into or out of CBHI schemes due to factors related to the outcome. In the ETPM proposed by Deb, Munkin, and Trivedi (2006), selection is modeled along with the hurdle and the expenditure equations. While selection on observables is handled by including confounding factors in the participation and the outcome equations, selection on unobservables is addressed by letting the error terms to be correlated. The third important issue is identification. We follow exclusion restriction to identify parameters in our system of equations. This issue is further 
discussed in section (4.3.) below.

\subsection{The Extended Two-Part Model}

Now, we present ETPM of endogenous CBHI enrolment and healthcare expenditure. Let $d_{i} \in\{0,1\}$ indicates CBHI enrollment status, $m_{i} \in[0, \infty)$ denotes spending, $s_{i} \in\{0,1\}$ is dummy (hurdle) variable indicating positive spending (i.e., $s_{i}=1\left(y_{i}>0\right)$ ). The expected healthcare expenditure is given by

$$
E\left[m_{i} \mid x_{i}, d_{i}, \Theta\right]=\operatorname{Pr}\left(s_{i}=1 \mid x_{i}, d_{i}, \Theta\right) E\left[m_{i} \mid s_{i}=1, x_{i}, d_{i}, \Theta\right],
$$

where $\Theta$ is a vector of model parameters, $x_{i}$ denotes a vector of covariates in the outcome equations, $\operatorname{Pr}\left(s_{i}=1 \mid x_{i}, d_{i}, \Theta\right)$ is the probability of positive spending, and $E\left[m_{i} \mid s_{i}=\right.$ $\left.1, x_{i}, d_{i}, \Theta\right]$ is the expected conditional amount of spending. In the ETPM, the probability of enrolling in $\mathrm{CBHI}$ schemes, the probability of positive spending, and the conditional amount of spending are modeled in a three-equation system, which can be written in latent variable forms as

$$
\begin{aligned}
& d_{i}^{*}=\beta^{d} w_{i}+\varepsilon_{i}^{d} \\
& s_{i}^{*}=\beta^{s} x_{i}+\gamma^{s} d_{i}+\varepsilon_{i}^{s} \\
& m_{i}^{*}=\beta^{m} x_{i}+\gamma^{m} d_{i}+\varepsilon_{i}^{m}
\end{aligned}
$$

where $d_{i}=1\left(d_{i}^{*}>0\right), s_{i}=1\left(s_{i}^{*}>0\right), y_{i}=1\left(s_{i}^{*}>0\right) \exp \left(m_{i}^{*}\right), 1(\cdot)$ is indicator operator, $\left\{d_{i}^{*}, s_{i}^{*}, m_{i}^{*}\right\}$ are the latent variables, $\left\{\gamma^{s}, \gamma^{m}\right\}$ are treatment effects parameters, $\left\{\beta^{d}, \beta^{h}, \beta^{y}\right\}$ are vectors of slope parameters to be estimated, and $\left\{\varepsilon_{i}^{d}, \varepsilon_{i}^{S}, \varepsilon_{i}^{m}\right\}$ are the error terms, and $w_{i}=$ $\left[x_{i} z_{i}\right]$ is a vector of covariates in the selection equation, $z_{i}$ is exogenous variable excluded from $x_{i}$.

We assume that the error terms are jointly and normally distributed as $\varepsilon_{i} \sim n\left(0, \Sigma_{3 \times 3}\right)$, where $\varepsilon_{i}=\left[\varepsilon_{i}^{d}, \varepsilon_{i}^{s}, \varepsilon_{i}^{m}\right]$. Because $d$ and $s$ are binary variables, we restrict the first two diagonal elements of $\Sigma$ to one. In the standard TPM, the hurdle and the expenditure equations are commonly assumed to be independent. Following the approach in Deb, Munkin, and Trivedi (2006), we assume that, conditional on $\varepsilon_{i}^{d}$, the error terms in (7b) and (7c) are independent, which can be written as

$$
\begin{aligned}
& \varepsilon_{i}^{s}=\sigma_{d s} \varepsilon_{i}^{d}+v_{i}^{s} \\
& \varepsilon_{i}^{m}=\sigma_{d m} \varepsilon_{i}^{d}+v_{i}^{m}
\end{aligned}
$$

where $\sigma_{d s}$ and $\sigma_{d m}$ are the covariances capturing selection on unobservables, $v_{i}^{S} \sim n(0,1)$ and $v_{i}^{m} \sim n\left(0, \sigma^{2}\right)$ are independent, and $\operatorname{corr}\left(\varepsilon_{i}^{d}, v_{i}^{s}\right)=0$ and $\operatorname{corr}\left(\varepsilon_{i}^{d}, v_{i}^{m}\right)=0$. Then, the conditional distributions of the hurdle and the expenditure variables can be written as 


$$
\begin{aligned}
& s_{i}^{*}=\beta^{s} x_{i}+\gamma^{s} d_{i}+\sigma_{d s} \varepsilon_{i}^{d}+v_{i}^{s} \\
& m_{i}^{*}=\beta^{m} x_{i}+\gamma^{m} d_{i}+\sigma_{d m} \varepsilon_{i}^{d}+v_{i}^{m} .
\end{aligned}
$$

In terms of the conditionals, the joint density of the observed data and the latent variables conditional on model parameters can be written as

$$
\begin{aligned}
p\left(d_{i}, s_{i}, m_{i}, d_{i}^{*}, s_{i}^{*}, m_{i}^{*} \mid w_{i}, X_{i}, \Theta\right)= & p\left(d_{i} \mid d_{i}^{*}, w_{i}, X_{i}, \Theta\right) \times p\left(d_{i}^{*} \mid w_{i}, X_{i}, \Theta\right) \\
\times & p\left(s_{i} \mid s_{i}^{*}, d_{i}^{*}, w_{i}, X_{i}, \Theta\right) \times p\left(s_{i}^{*} \mid d_{i}^{*}, w_{i}, X_{i}, \Theta\right) \\
\times & p\left(m_{i} \mid m_{i}^{*}, s_{i}^{*}, s_{i}, d_{i}^{*}, w_{i}, X_{i}, \Theta\right) \times \\
& p\left(m_{i}^{*} \mid s_{i}^{*}, s_{i}, d_{i}^{*}, w_{i}, X_{i}, \Theta\right),
\end{aligned}
$$

where $X_{i}=\left[x_{i} T_{i} \varepsilon_{i}^{d}\right]$. Due to data augmentation, the likelihood function is expanded and the latent variables are drawn from their conditional distributions (Tanner and Wong, 1987; Albert and Chib, 1991). The joint posterior distribution of parameters and latent variables, which is proportional to the product of the likelihood function, the posteriors of the parameters, and the priors, can be compactly written as

$$
p\left(\Theta, d_{i}^{*}, s_{i}^{*}, m_{i}^{*} \mid d_{i}, s_{i}, m_{i}, w_{i}, X_{i}\right) \propto\left[p\left(d_{i}, s_{i}, m_{i}, d_{i}^{*}, s_{i}^{*}, m_{i}^{*} \mid w_{i}, X_{i}, \Theta\right)\right] p(\Theta) p\left(\Theta_{0}\right) .
$$

The set of parameters to be estimated are $\Theta=\left\{\beta^{d}, \beta^{s}, \beta^{m}, \gamma^{s}, \gamma^{m}, \sigma_{d s}, \sigma_{d m}, \sigma_{m}^{2}\right\}$.

The next step is to specify the priors. We choose priors similar to those specified in Deb, Munkin, and Trivedi (2006). In particular, we specify non-informative conjugate normal distributions for all slope parameters with mean zero and variance 10 (i.e., $N\left(\mu_{0}=0, V_{0}=\right.$ $\left.10 I_{K}\right)$ ), and inverse gamma distribution for the variance $\sigma_{m 0}^{2} \sim i g\left(\frac{v}{2},\left(\frac{c}{2}\right)^{-1}\right)$, where $v=10$ and $c=5$. The priors on the covariance parameters $\sigma_{d s}$ and $\sigma_{d m}$ are specified to be informative conjugate normal distributions, which is necessary to conduct hypothesis testing using Savage-Dickey ratio of Bayes Factor. In particular, we specify a normal distribution with mean zero and variance 0.5 (i.e., $N\left(0, \frac{1}{2} I\right)$ ). We check sensitivity of the test results with tighter priors of $N\left(0, \frac{1}{5} I\right)$ and $N\left(0, \frac{1}{8} I\right)$.

The MCMC estimation algorithm for multinomial probit selection equation can be found in Deb, Munkin, and Trivedi (2006). We tailored the algorithm to fit our model of ETPM with binary selection equation, which is summarized in Box 1 and detailed in Appendix A.

\subsection{Treatment Effects}

Once the post-convergence model parameters are obtained, the next step is to calculate the treatment effects. For each individual the effect of CBHI on out-of-pocket expenditure is 
given by

$$
T E_{i} \mid \theta=E\left[m_{i} \mid x_{i}, d_{i}=1, \theta\right]-E\left[m_{i} \mid x_{i}, d_{i}=0, \theta\right],
$$

where the conditional expected expenditure with the appropriate log retransformation is given by

$$
\begin{aligned}
E\left[m_{i} \mid x_{i}, d_{i}, \theta\right] & =\Phi\left(\beta^{s} x_{i}+\gamma^{s} d_{i}+\sigma_{d s}\left(d_{i}^{*}-\beta^{d} w_{i}\right)\right) \\
& \times \exp \left\{\beta^{m} x_{i}+\gamma^{m} d_{i}+\sigma_{d m}\left(d_{i}^{*}-\beta^{d} w_{i}\right)+\frac{1}{2} \sigma_{m}^{2}\right\} .
\end{aligned}
$$

Then, the conditional TE is integrated over the model parameters to obtain the unconditional values. This is done using Monte Carlo integration over the post-convergence vector of parameter draws $\tilde{\theta}_{R}$ as follows

$$
\widehat{T E}_{\iota}=E_{\theta}\left[T E_{i} \mid \theta\right] \approx \frac{1}{R} \sum_{r=1}^{R} T E_{i}\left(\tilde{\theta}_{r}\right) .
$$

From equation (9), we can obtain the standard average treatment effects $\left(A T E=\frac{1}{N} \sum_{i=1}^{N} \widehat{T E}_{l}\right)$, average treatment effects on the treated $\left(A T T=\frac{\sum_{i=1}^{N} d_{i} T \mathbb{E}_{l}}{\sum_{i=1}^{N} d_{i}}\right)$ and the average treatment effects on the untreated $\left(A T U T=\frac{\sum_{i=1}^{N}\left(1-d_{i}\right) \widehat{T E}_{l}}{\sum_{i=1}^{N}\left(1-d_{i}\right)}\right)$.

\subsection{Test of Endogeneity in CBHI Enrollment}

There are different approaches for hypothesis testing in the Bayesian framework. The popular and simpler approach is to use Bayes factor calculated using Savage-Dickey density ratio or Gelfrand-Dey approaches. Since the standard TPM is nested in the ETPM, we use the Savage-Dickey density ratio approach, which is simple and appropriate for nested models (Deb, Munkin, and Trivedi, 2006; Li and Trivedi, 2014). We are interested to test the null hypothesis that $\mathrm{CBHI}$ enrollment is exogenous $\left(H_{0}: \sigma_{d s}=\sigma_{d m}=0\right)$. Then, the Savage-Dickey Bayes factor is given by

$$
B_{0,1}=\frac{p\left(\sigma_{d s}=0, \sigma_{d m}=0 \mid X, \theta\right)}{p\left(\sigma_{d s}=0, \sigma_{d m}=0\right)} .
$$

The numerator in equation (15) is the joint posterior density of $\sigma_{d s}$ and $\sigma_{d m}$ evaluated at zero, whereas the denominator is the prior density evaluated at zero. Specifically, $p\left(\sigma_{d s}=\right.$ $0, \sigma_{d m}=0$ ) is calculated form a multivariate normal pdf with mean $0_{2 \times 1}$ and covariance matrix $\frac{1}{2} I_{2}$ evaluated at zero. The numerator, on the other hand, is calculated from the joint conditional posterior pdf using post-convergence parameters $\tilde{\theta}_{r}$ as 


$$
p\left(\sigma_{d s}=0, \sigma_{d m}=0 \mid X, \theta\right) \approx \frac{1}{r} \sum_{i=1}^{R} p\left(\sigma_{d s}=0, \sigma_{d m}=0 \mid X, \tilde{\theta}_{r}\right)
$$

The data favors the null hypothesis if the Savage-Dickey Bayes factor is greater than one, otherwise the alternative.

\subsection{Identification through exclusion restriction}

We identify model parameters of the ETPM through cross-equation exclusion restriction. The idea is to include exogenous variable(s) which affect(s) CBHI enrollment but not correlated with out-of-pocket expenditure. Such approach is sufficient to identify model parameters and is commonly applied in the literature (Deb, Munkin, and Trivedi, 2006, Li and Tobias, 2011; Kean and Stavrunova, 2014; Munkin and Trivedi, 2010; Li and Trivedi, 2014).

We use membership in microfinance institutions as exclusion variable. The argument is that households who participate in microfinance activities are familiar with other community-based financial schemes, such as $\mathrm{CBHI}$ and are more likely to participate due to peer influence, for instance. We argue that microfinance participation is exogenous that can be excluded from health expenditure equations. One of the concern is that membership microfinance could be related to out-of-pocket healthcare expenditure through its effect on income. As such, microfinance member households could have systematically different characteristics which are related to their CBHI enrollment decisions and out-of-pocket expenditure. In order to rule out such possibility, we conducted a balancing test whether the observed characteristics of microfinance members and non-members using covariate balancing test. This is common in propensity score matching analysis (Austin, 2009). The test shows that all the covariates included in the model are well balanced between microfinance members and non-member households (see Table B.1 in Appendix B). This implies that the two groups are similar to each other and one can argue that if membership in microfinance affects out-of-pocket spending it must be through households' decision to enroll in CBHI not through its income effect.

Finally, although there is no definite method of establishing exogeneity, we conduct overidentification tests by jointly excluding microfinance membership and cluster level CBHI membership rate to further strengthen our argument. The test results from the overidentification test suggest that the model is overidentified in the classical two-stage estimation.

\section{The Data}

We use three rounds of nationally representative data from the Rwandan Integrated Household Living Conditions Surveys (Enquete Intégrale sur les Conditions de Vie des ménages de Rwanda (EICV)) conducted in 2000, 2005, and 2010. The EICV surveys collect information on household demographics, socio-economic characteristics, health, health insurance status, expenditures, incomes, wealth, etc. as well as area-level characteristics. 
While information on health insurance status is recorded at the individual level, expenditure on healthcare is recorded at the household level. We categorize households as "treated" if any member in the household is enrolled in CBHI schemes and "untreated," otherwise.

Table (1) presents the proportion of households with at least one family member enrolled in different health insurance schemes. Because the CBHI program took effect in 2004, the 2000 survey provides us with pre-intervention information. The proportion of households with at least one family member enrolled in CBHI schemes were 42 percent and 76 percent $^{3}$ in 2005 and 2010, respectively. About 5 percent of households have at least one family member covered through employment-based health insurance (RAMA, MMI, or other private health insurance). Since we focus on comparing out-of-pocket spending among households who are enrolled in CBHI and the uninsured, our analysis excludes households with formal health insurance coverage. The final pooled sample includes 26,195 households (6,390 from 2000; 6,259 from 2005; and 13,546 from 2010 surveys).

The survey also collects household-level information on specific healthcare spending including spending on consultation visits, screening, hospital, drug, birth, and other expenses (such as durable medical equipment, health-related transportation and accommodation, etc.). Expenditure information are collected in different modules and recall times depending on the frequency of purchases (one week, four weeks, and 12 months), which we aggregate to an annual per capita spending levels. Furthermore, we deflate all values to year 2000 prices using the National Institute of Statistics regional consumer price index.

Table (2) shows the simple averages of out-of-pocket spending on overall healthcare, outpatient, inpatient, and drug. The data show that per capita out-of-pocket spending on various healthcare services has considerably decreased over the years. For instance, the overall per capita spending in 2010 for the insured (uninsured) is almost half (one-fourth) of the spending in 2000. Similarly, spending on specific healthcare services has declined, which could be attributed to many factors including availability of health insurance (CBHI schemes), improved physical access to healthcare facilities at a lower cost and overall healthcare delivery system, and so on.

When it comes to out-of-pocket spending by insurance status, in 2005, except on inpatient services, the uninsured spend higher amount than the insured. The converse is true in 2010, where CBHI member households spend higher amount on overall, outpatient, and inpatient services but lower amount on drug. One of the issues in these averages is that there is high proportion of zeros in the data, which is problematic if the proportion systematically differs by insurance status or other characteristics. Figure (1) shows the distribution of overall, outpatient, inpatient, and drug spending by insurance status where there is high proportion of

\footnotetext{
${ }^{3}$ Administrative records show that the national CBHI enrollment rate is 91 percent in 2010 and 83 percent in 2011 (MoH Annual Report, 2011). Such disparities between national level administrative reports and averages from household surveys are expected.
} 
zeros, which also vary by CBHI status. This issue is addressed in our ETPM framework.

Summary of control variables included in the analysis is presented in Table (3), which includes household demographic characteristics, number of individuals with illnesses, consumption and wealth quintiles, occupation, education, and location of residence. While consumption quartiles are constructed from per capita annual consumption expenditure for each survey year, wealth quartiles are constructed from a composite wealth index. The wealth index is calculated using principal component analysis on the number of agricultural equipment, livestock, household durables, dwelling characteristics, and size of land owned by the household. We include 29 district dummies to capture spatial variation in community-level factors including distance, geography, number of hospitals, number of clinics, the number of healthcare providers and other supply side factors.

\section{RESUlts AND Discussions}

\subsection{Participation and Endogeneity}

Tables (4)-(8) present posterior means and standard deviations of coefficients for overall, outpatient, inpatient and drug spending models. The estimates suggest that household-level demographic characteristics such as age, sex and marital status of the head, and household size are statistically significant factors in CBHI enrollment. While households with older and married heads are more likely to enroll their family members in CBHI schemes, households with male head, larger family size, and no education are less likely to enroll their family members. Health conditions, as measured by the number of individuals with major illnesses, also significantly affect CBHI enrollment. Similarly, income and wealth levels significantly affect households' enrollment decisions in that the well-to-dos are more likely to enroll their family members in CBHI schemes than households in the bottom income and wealth quartiles. From equity perspective, these results highlight that the schemes' premium and benefit structures are somehow unfavorable for the poor. If "inclusiveness" is one of the objectives, there is little or no evidence that the Rwandan CBHI program has succeeded in providing affordable health insurance for the poor.

The results also show that district and year dummies are statistically significant in CBHI enrollment decision, implying spatial and temporal variations at the district and national levels. In particular, compared to year 2000, households in year 2010 are more likely to be enrolled in CBHI schemes. Furthermore, membership in microfinance institutions is statistically significant in all models.

As shown in Tables (4)--(8), the "Hurdle" and the "Expenditure" columns, most of the control variables are "confounding" factors, significantly affecting both CBHI enrollment and the outcome variables. For instance, households with a large number of sick individuals are less likely to enroll in CBHI but are more likely to spend. They are also more likely to spend higher amount conditional on spending. Similarly, households with higher incomes are more likely to enroll in CBHI schemes and spend more on healthcare from out-of-pocket. 
These results substantiate the importance of selection on observable factors where individuals self-select into or out of CBHI based on their demographic, socio-economic, geographic, and other characteristics.

In addition to observed factors, unobserved factors - such as preference towards insurance, underlying health conditions, and risk aversion - play significant role in both CBHI enrollment and out-of-pocket spending behavior. If these factors are not accounted for in the empirical model, the estimated treatment effects could be biased. The ETPM accounts for such bias arising from endogeneity or selection on unobserved factors. We formally test the null hypothesis of no endogeneity $\left(H_{0}: \sigma_{d h}=\sigma_{d y}=0\right)$ using the Savage-Dickey Bayes Factor. For $v_{0}=\frac{1}{2}$, the data strongly reject the null for overall, outpatient, and drug spending models. The test is consistent for less informative prior selections $\left(v_{0}=2 ; v_{0}=1\right)$ and more informative selections $\left(v_{0}=\frac{1}{2} ; v_{0}=\frac{1}{5}\right.$; and $\left.v_{0}=\frac{1}{8}\right)$, which gives Savage-Dickey ratios of zero or very close to zero. However, the data could not reject the null for inpatient spending model, which gives a Savage-Dickey ratio of 22.2. This implies that in the inpatient spending model CBHI membership can be considered as exogenous. In general, the test results underscore that if selection bias is ignored, the estimated treatment effects would be significantly biased.

\subsection{Treatment Effects}

Table (9) presents the ATEs on the probability and the amount of spending. For comparison, we also report treatment effects from the standard TPM under the assumption of random (exogenous) CBHI enrollment. The differences between the results from these two models show that the magnitude and the direction of selection bias when endogeneity is ignored.

For the most part, CBHI has a non-linear effect increasing the probability but decreasing the amount of spending. The results from the ETPM show that the ATE on the probability of spending on overall healthcare services is 31.8 percentage points whereas the ATE on the amount of spending is $-3,609$ Rwandan francs. On the other hand, the scheme increases the probability and the amount of spending on outpatient services by 34.5 percentage points and RWF346, respectively.

The program also reduces the amount of annual per capita spending on drug by RWF3,553, which is about 83 percent reduction compared to baseline level of average spending by the uninsured. This seems particularly perplexing since the program does not cover nonessential drugs obtained from establishments outside health facilities covered by the CBHI schemes. However, the insured have better access to clinics and hospitals where some of the drugs are covered by their insurance plans and are free of extra charges. In addition, given the prevalence of "self-medication," using non-prescription drugs from neighborhood pharmacies and stores, it is not uncommon for the uninsured to spend higher amount on drug. As a result, although all drugs are not covered by CBHI schemes, it is still likely to find 
significant impact on drug spending. When it comes to inpatient services, which is mainly hospitalization, the impact is neither economically nor statistically significant.

Because the 2005 and the 2010 enrollment package and premium schedules differ, we estimate overall spending net of premium payments to see how the impact changes. In this case, $\mathrm{CBHI}$ increases the probability of spending by 28.6 percentage points but decreases the amount of spending net of premium payment by RWF4,106 (see Table 9). This shows that even if the premium schedule and benefit packages have changed over the years, the qualitatively and quantitative impacts of CBHI on out-of-pocket spending remain consistent and statistically significant.

Turning to endogeneity, the bias tends to attenuate the effects of CBHI to zero. For instance, in Table 9, the estimated ATE on overall healthcare spending using standard TPM is positive and significant. If endogeneity is disregarded, that is., enrollment is assumed to be exogenous, the ATE on overall spending would be biased by about RWF3,820 (RWF210 vs -3609 RWF). This is mainly because CBHI enrolled households spend more on overall healthcare services, compared to the uninsured, even in the absence of insurance as shown by the high positive $(0.886$ (std. dev. $=0.013)$ ) covariance between $\mathrm{CBHI}$ and the amount of expenditure. Ignoring this would lead to underestimation of the CBHI effect on out-of-pocket healthcare expenditure.

The other important issue is heterogeneity in treatment effects. To shed some light on heterogeneity, we plot individual level-treatment effects for the treated, the untreated and the whole sample in Figures (2a) - (2e). The figures show considerable heterogeneity in the estimated treatment effects. The treatment effects on overall and drug spending are mainly in the negative domain but vary across households, whereas treatment effects on outpatient and inpatient spending are on both the negative and the positive domains highlighting the heterogeneous impact of CBHI. To assess how treatment effects vary by observed factors, we also plot their distributions by age, income and wealth percentiles (see Figures (3)-(6)). In all models, there is strong indication that ATEs vary by age, income and wealth distributions. For instance, the effects of CBHI on overall spending is "u-shape" with higher reduction in out-of-pocket spending for households with heads aged between 20 and 60. Interestingly, the ATEs increase as households' position in the income distribution increases to the top percentile favoring the better off households. The reverse is true in the case of outpatient spending in which CBHI increases spending.

\subsection{Sensitivity Analysis}

Specifying informative priors on the covariance $\left(\sigma_{d s}, \sigma_{d m}\right)$ is necessary to conduct hypothesis testing using Savage-Dickey method. However, it also causes the posteriors to be pulled towards the priors, which could be propagated across model parameters and estimated treatment effects. Hence, it is important to assess the sensitivity of estimated treatment effects to our prior choices. Specifically, we estimate the model using less informative prior 
selections $\left(v_{0}=2\right.$ and $\left.v_{0}=1\right)$ and more informative selections $\left(v_{0}=\frac{1}{5}\right.$ and $\left.v_{0}=\frac{1}{8}\right)$. The results from this exercise are presented in Table (10). We can see that the magnitude and the direction of treatment effects remain stable regardless of prior selections. In addition, the Savage-Dickey ratios remain the same, rejecting the null for the overall out-of-pocket expenditure model. The sensitively analysis indicates that the results are robust to different prior selections.

However, consideration of other issues is in order. For instance, it is important to note that our results could be potentially biased due to measurement error in expenditure data which are self-reported. In particular, if measurement errors systematically vary by CBHI status (for instance, if the insured tend to over-report their spending than the uninsured), the results could be biased.

\section{Concluding Remarks}

Households in many low-income countries are exposed to the financial risks of large medical bills in the absence of third party and prepayment systems - such as health insurance and tax-based healthcare financing. In recent years, CBHI schemes have become popular alternatives to fill such void in the healthcare financing systems. However, the existing evidence on the impact of CBHI schemes on out-of-pocket healthcare spending is limited, especially in the African context. In this paper, using nonrandomized household survey data from Rwanda, we investigate the impact of CBHI schemes on overall out-of-pocket spending and its components. We address issues of selection bias in health insurance enrollment and censoring in health expenditure using ETPM.

Our results show that CBHI has significant non-linear impact on out-of-pocket spending, increasing the likelihood of spending but decreasing the conditional amount of spending. When it comes to specific components, the impacts are mixed. While the program significantly decreases spending on drug and increases spending on outpatient visits, it has no significant effect on inpatient spending. The results also show some degree of heterogeneity where the highest reduction in out-of-pocket spending is among households in the top income and wealth percentiles. 


\section{Tables and Figures}

Figure 1. Histogram of Log of Out-of-Pocket Healthcare Spending on Overall, Outpatient, Inpatient, and Drug Expenditures

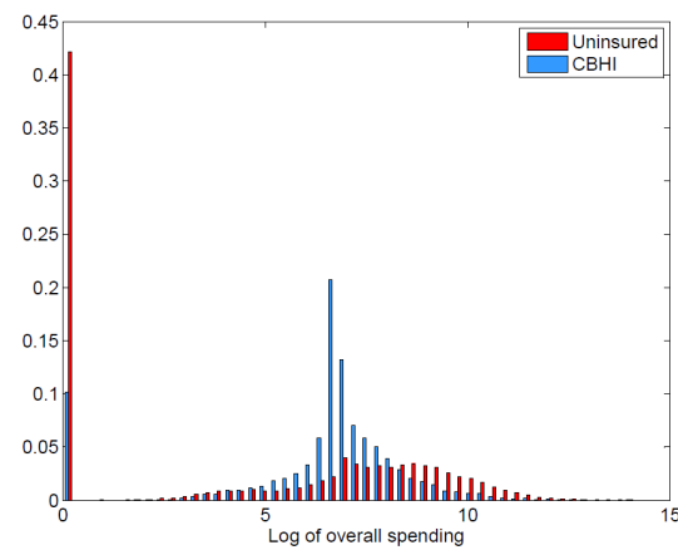

(a) Overall

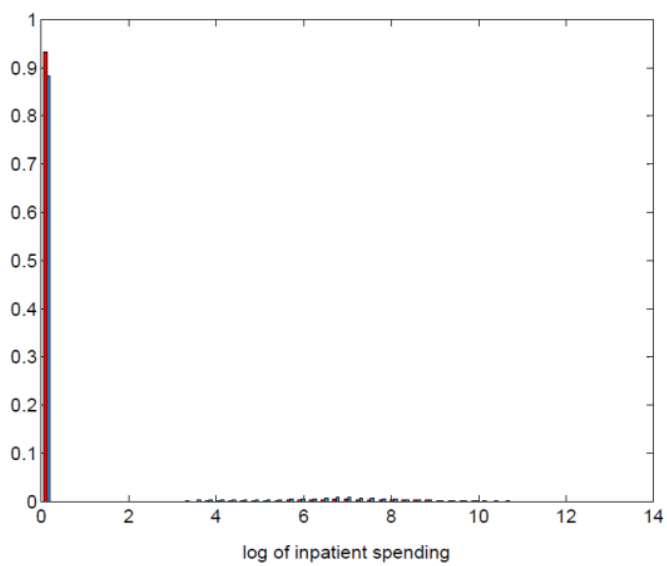

(c) Inpatient

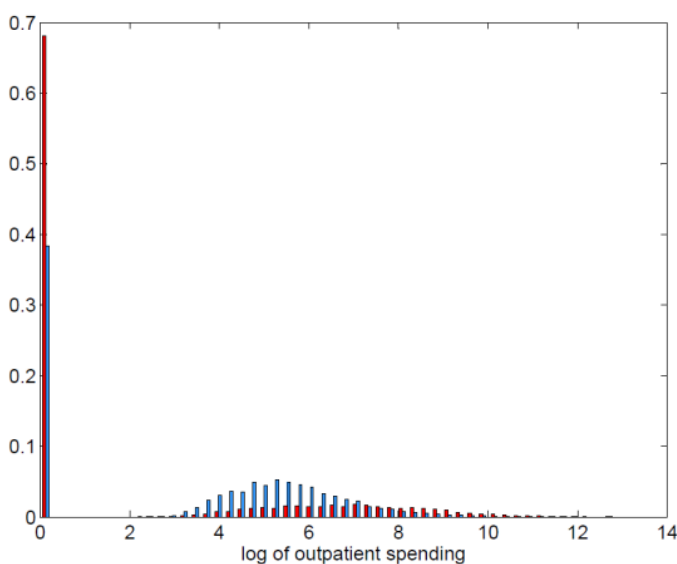

(b) Outpatient

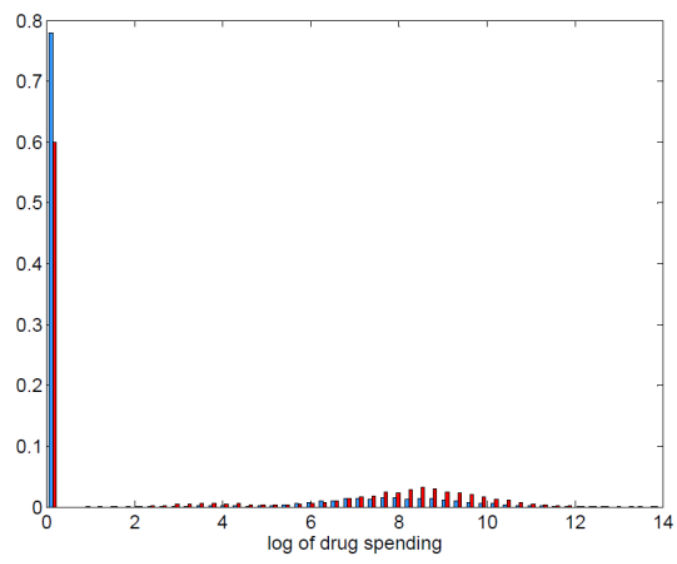

(d) Drug 
Figure 2. Kernel Density of Treatment Effects
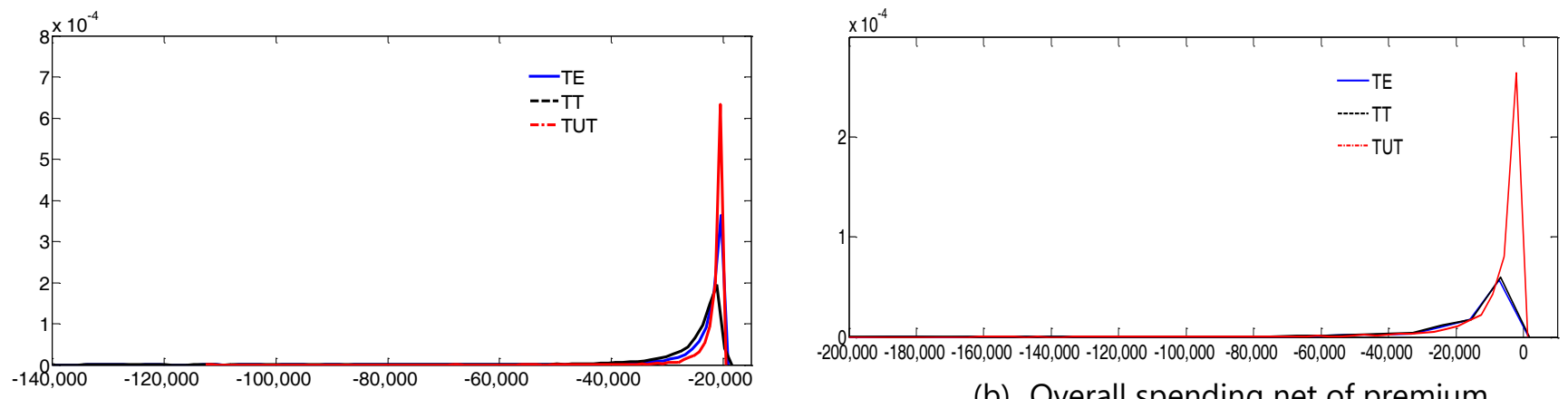

(a) Overall spending

(b) Overall spending net of premium

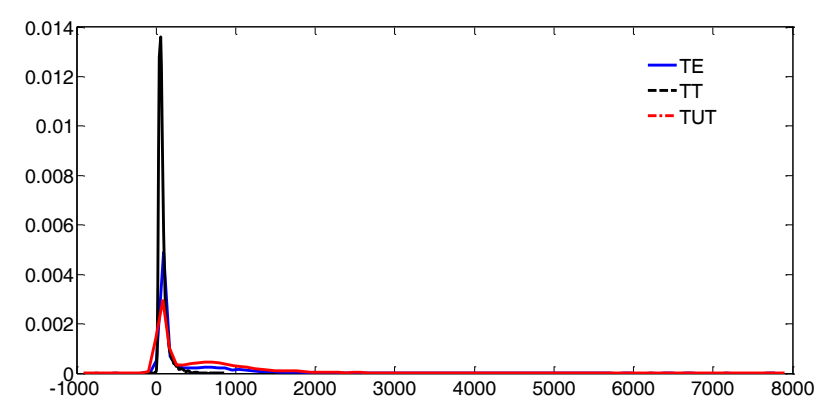

(c) Outpatient spending

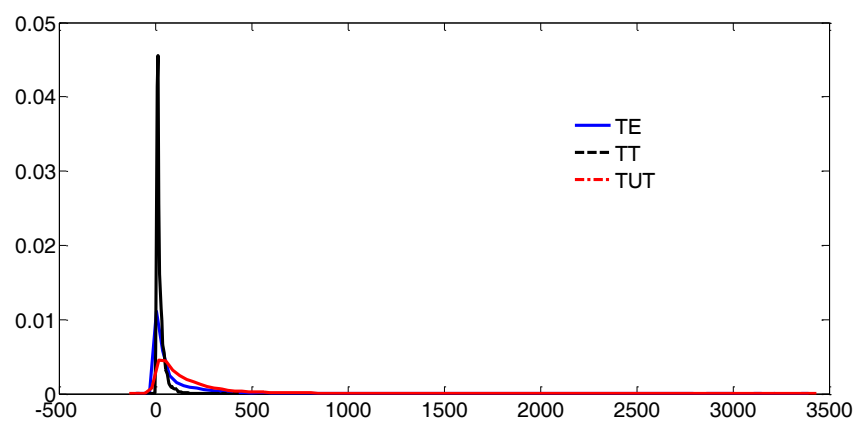

(d) Inpatient spending

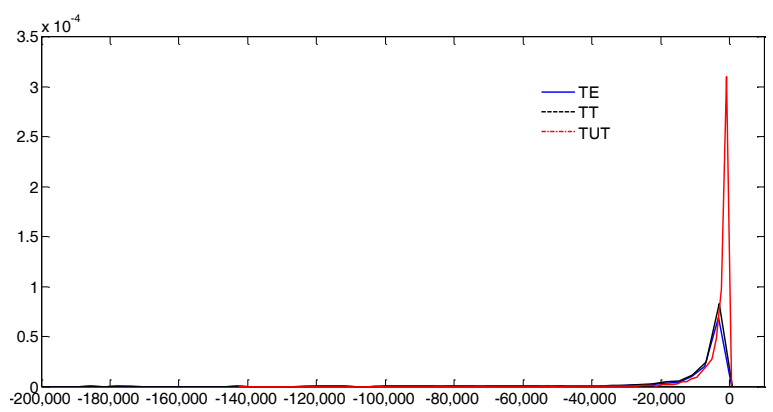

(e) Drug spending 
Figure 3. ATE on Overall Out-Of-Pocket Expenditure by Age, Income, and Wealth Percentiles
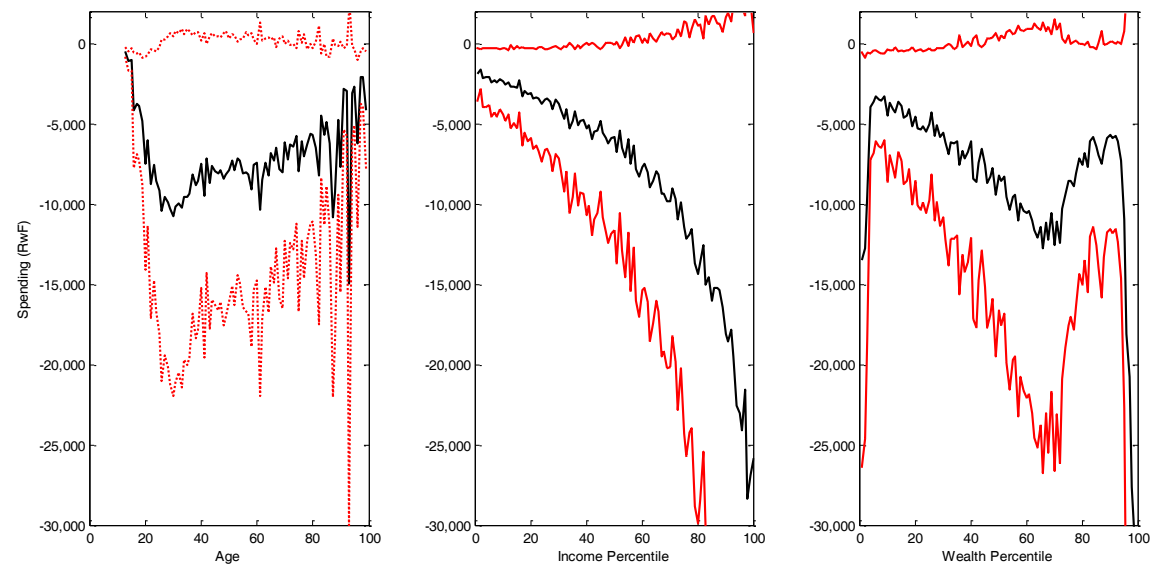

Figure 4. ATE on Outpatient Expenditure by Age, Income and Wealth Percentiles
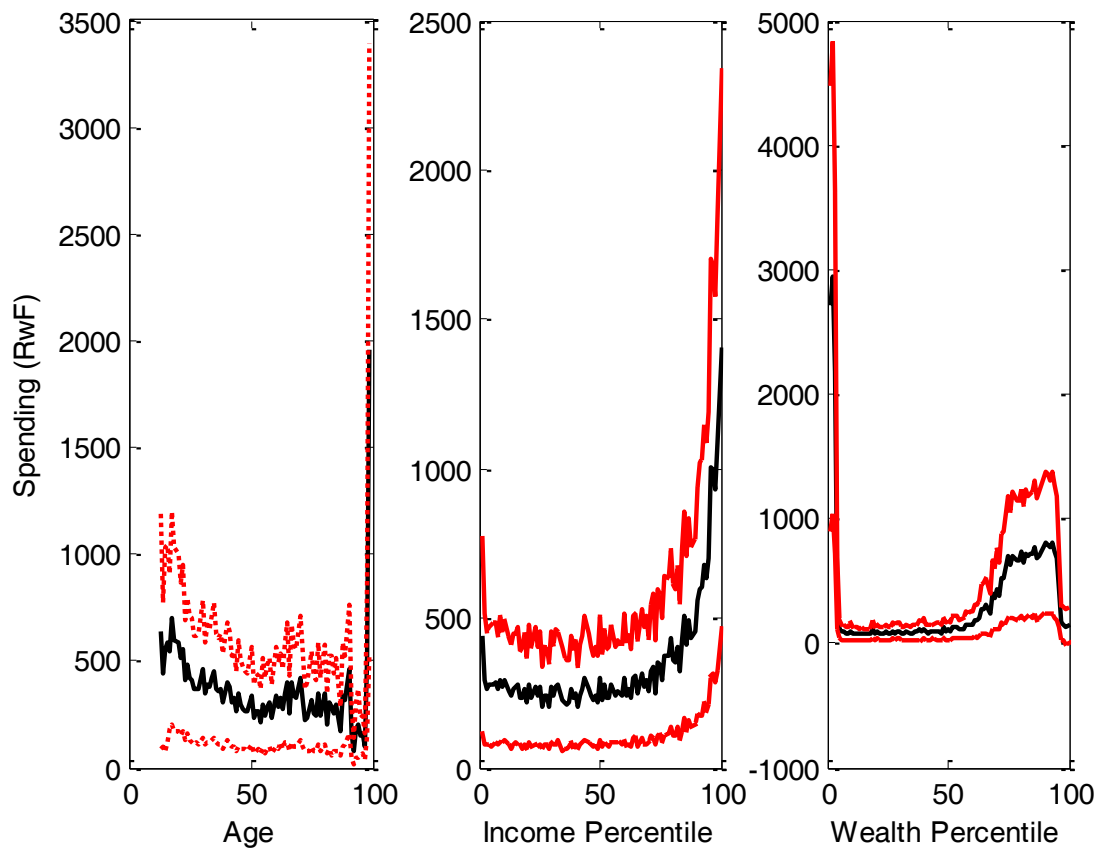

CInternational Monetary Fund. Not for Redistribution 
Figure 5. ATE on Inpatient Expenditure by Age, Income, and Wealth Percentiles
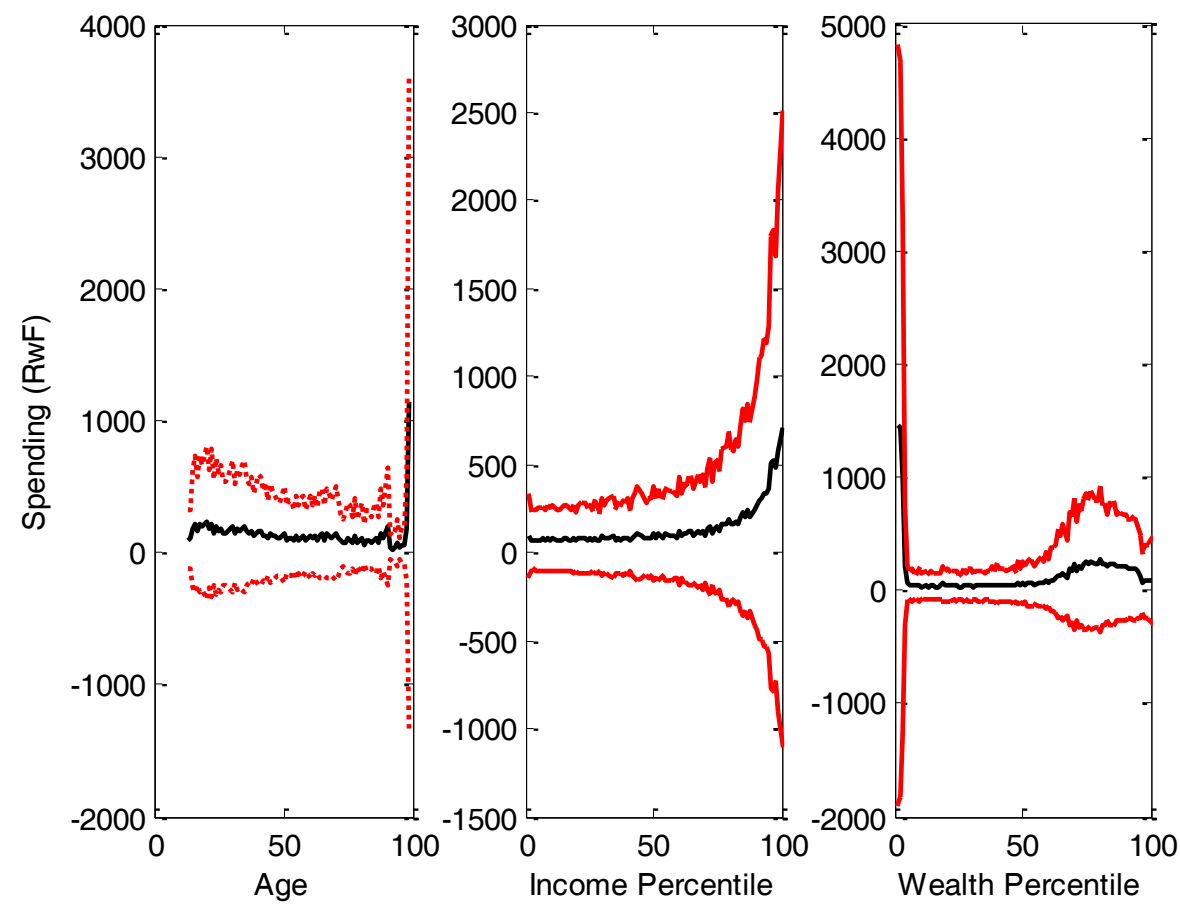

Figure 6. ATE on Drug Expenditure by Age, Income, and Wealth Percentiles
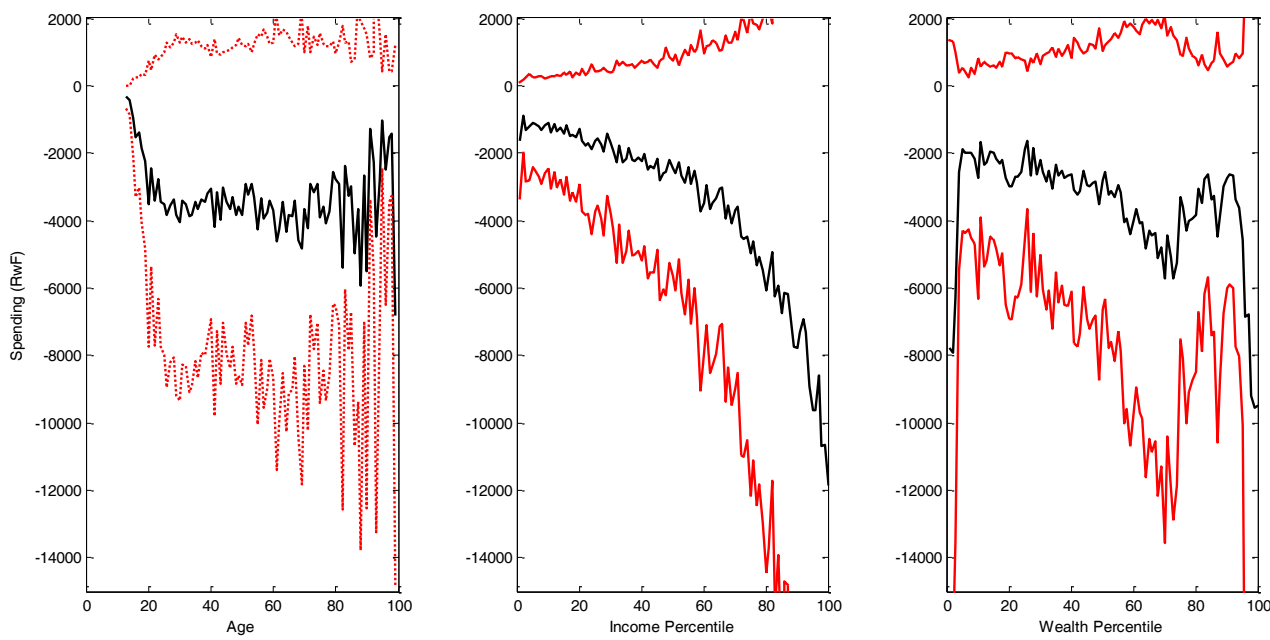
Table 1. Health Insurance Status

\begin{tabular}{lccc}
\hline & $\begin{array}{c}2000 / 2001 \\
\text { (baseline) }\end{array}$ & $2005 / 2006$ & $2010 / 2011$ \\
\hline CBHI & $0 \%$ & $41.9 \%$ & $75.8 \%$ \\
Other formal insurance (MMI, RAMA, private, & n.a. & $9.1 \%$ & $5.3 \%$ \\
etc.) & $100 \%$ & $51.0 \%$ & $22.2 \%$ \\
Uninsured & 6,390 & 6,900 & 14,308 \\
\hline
\end{tabular}

Table 2. Per Capita Out-of-Pocket Healthcare Spending (RWF) in 2000 Prices

\begin{tabular}{lcccccc}
\hline & & 2000 & \multicolumn{2}{c}{$2005 / 2006$} & \multicolumn{2}{c}{$2010 / 2011$} \\
& Pooled & & & \multicolumn{2}{c}{} \\
& Sample & Uninsured & Uninsured & CBHI & Uninsured & CBHI \\
\hline Overall & 2,612 & 4,352 & 2,665 & 1,852 & 928 & 2,233 \\
& $(14,297)$ & $(19,448)$ & $(6,882)$ & $(7,576)$ & $(4,143)$ & $(15,596)$ \\
Overall less premium & 2,444 & 4,352 & 2,665 & 1,852 & 824 & 1,842 \\
& $(14,294)$ & $(19,448)$ & $(6,882)$ & $(7,576)$ & $(4,136)$ & $(15,575)$ \\
Outpatient & 417 & 885 & 376 & 304 & 145 & 254 \\
& $(2,717)$ & $(4,419)$ & $(1,732)$ & $(1,337)$ & $(787)$ & $(2,171)$ \\
Drug & 1,228 & 2,860 & 1,914 & 1,113 & 321 & 295 \\
& $(7,016)$ & $(12,321)$ & $(5,718)$ & $(6,479)$ & $(1,681)$ & $(2,140)$ \\
Hospital & 281 & 566 & 307 & 382 & 34 & 146 \\
& $(4,780)$ & $(8,495)$ & $(1,608)$ & $(2,554)$ & $(319)$ & $(3,227)$ \\
\hline No. of obs. & 26243 & 6420 & 3518 & 2751 & 3169 & 10385 \\
\hline
\end{tabular}


Table 3. Descriptive Statistics of Control Variables

\begin{tabular}{|c|c|c|c|c|c|}
\hline & \multirow{2}{*}{$\begin{array}{l}2000 / 2001 \\
\text { Uninsured }\end{array}$} & \multicolumn{2}{|c|}{$2005 / 2006$} & \multicolumn{2}{|c|}{$2010 / 2011$} \\
\hline & & Uninsured & $\mathrm{CBHI}$ & Uninsured & $\mathrm{CBHI}$ \\
\hline \multirow[t]{2}{*}{ Head: Age } & 43.71 & 43.30 & 45.14 & 44.23 & 45.63 \\
\hline & (15.02) & $(15.63)$ & (15.09) & $(16.04)$ & (15.97) \\
\hline \multirow[t]{2}{*}{ Household size } & 5.02 & 4.70 & 5.31 & 4.43 & 4.83 \\
\hline & $(2.34)$ & $(2.27)$ & $(2.30)$ & $(2.08)$ & $(2.17)$ \\
\hline \multirow[t]{2}{*}{ Mean age in the household } & 22.72 & 23.44 & 23.10 & 24.71 & 24.62 \\
\hline & $(10.44)$ & $(11.31)$ & $(10.26)$ & $(13.28)$ & $(11.48)$ \\
\hline Head: male & $68.5 \%$ & $69.4 \%$ & $74.4 \%$ & $69.1 \%$ & $72.2 \%$ \\
\hline Head: married & $17.6 \%$ & $45.7 \%$ & $60.3 \%$ & $45.9 \%$ & $57.1 \%$ \\
\hline \multirow{2}{*}{ No. of individuals w/ illnesses } & 1.25 & 0.99 & 0.95 & 0.84 & 0.83 \\
\hline & $(1.30)$ & $(1.18)$ & $(1.12)$ & $(1.08)$ & $(1.04)$ \\
\hline Cons. expenditure: 1 st quartile & $25.0 \%$ & $32.0 \%$ & $19.1 \%$ & $36.2 \%$ & $23.2 \%$ \\
\hline Cons. expenditure: 2 nd quartile & $25.0 \%$ & $25.8 \%$ & $26.6 \%$ & $29.3 \%$ & $25.1 \%$ \\
\hline Cons. expenditure: 3rd quartile & $25.0 \%$ & $23.3 \%$ & $29.4 \%$ & $23.0 \%$ & $26.6 \%$ \\
\hline Cons. expenditure: 4 th quartile & $25.0 \%$ & $18.9 \%$ & $24.9 \%$ & $11.6 \%$ & $25.1 \%$ \\
\hline Wealth index: 1st quartile & $25.1 \%$ & $32.4 \%$ & $19.1 \%$ & $41.6 \%$ & $21.5 \%$ \\
\hline Wealth index: 2nd quartile & $25.1 \%$ & $27.4 \%$ & $24.6 \%$ & $29.3 \%$ & $25.1 \%$ \\
\hline Wealth index: 3rd quartile & $25.1 \%$ & $22.6 \%$ & $30.0 \%$ & $19.7 \%$ & $27.7 \%$ \\
\hline Wealth index: 4 th quartile & $24.8 \%$ & $17.7 \%$ & $26.4 \%$ & $9.4 \%$ & $25.7 \%$ \\
\hline Head's educ.: primary & $25.2 \%$ & $57.0 \%$ & $59.5 \%$ & $63.0 \%$ & $62.7 \%$ \\
\hline \multicolumn{6}{|l|}{ Head's educ.: } \\
\hline Secondary/vocational/tertiary & $3.6 \%$ & $8.0 \%$ & $10.0 \%$ & $4.6 \%$ & $8.5 \%$ \\
\hline Head's educ.: No education & $70.7 \%$ & $34.4 \%$ & $29.9 \%$ & $32.2 \%$ & $28.3 \%$ \\
\hline \multirow[t]{2}{*}{ No. of wage earner in the household } & 0.54 & 0.93 & 0.84 & 1.76 & 1.43 \\
\hline & $(0.88)$ & $(1.02)$ & $(1.03)$ & $(1.45)$ & $(1.41)$ \\
\hline Urban & $22.9 \%$ & $24.5 \%$ & $14.7 \%$ & $12.3 \%$ & $13.6 \%$ \\
\hline No. of households & 6,390 & 6,259 & & 13,546 & \\
\hline
\end{tabular}


Table 4. Overall Healthcare Expenditure: ETPM Posterior Means and Standard Deviations

\begin{tabular}{|c|c|c|c|c|c|c|}
\hline & \multicolumn{2}{|c|}{$\mathrm{CBHI}$} & \multicolumn{2}{|c|}{ Hurdle } & \multicolumn{2}{|c|}{ Expenditure } \\
\hline & Mean & Std.Dev. & Mean & Std.Dev. & Mean & Std.Dev. \\
\hline Intercept & -1.633 & $(0.096)$ & -0.681 & $(0.080)$ & 7.049 & $(0.100)$ \\
\hline $\mathrm{CBHI}$ & & & 1.262 & $(0.084)$ & -1.659 & $(0.035)$ \\
\hline Head: age & 0.006 & $(0.001)$ & -0.008 & $(0.001)$ & 0.004 & $(0.001)$ \\
\hline Head: male & -0.348 & $(0.036)$ & 0.114 & $(0.028)$ & -0.122 & $(0.037)$ \\
\hline Head: married & 0.565 & $(0.032)$ & -0.004 & $(0.029)$ & 0.215 & $(0.033)$ \\
\hline $\mathrm{HH}:$ size & -0.016 & $(0.007)$ & 0.016 & $(0.005)$ & -0.186 & $(0.006)$ \\
\hline \multicolumn{7}{|l|}{$\mathrm{HH}$ : \#of individuals w/ } \\
\hline illness & -0.056 & $(0.012)$ & 0.359 & $(0.012)$ & 0.285 & $(0.011)$ \\
\hline Head educ.: primary & 0.312 & $(0.027)$ & 0.005 & $(0.024)$ & 0.195 & $(0.028)$ \\
\hline Head edu.: sec/voc/univ & 0.510 & $(0.054)$ & 0.031 & $(0.052)$ & 0.417 & $(0.051)$ \\
\hline \# of wage earners & -0.003 & $(0.008)$ & 0.000 & $(0.009)$ & & \\
\hline $2^{\text {nd }}$ cons. quartile & 0.112 & $(0.034)$ & 0.260 & $(0.028)$ & 0.385 & $(0.036)$ \\
\hline $3^{\text {rd }}$ cons. quartile & 0.179 & $(0.037)$ & 0.469 & $(0.030)$ & 0.735 & $(0.038)$ \\
\hline $4^{\text {th }}$ cons. quartile & 0.307 & $(0.044)$ & 0.759 & $(0.036)$ & 1.436 & $(0.044)$ \\
\hline $2^{\text {nd }}$ wealth quartile & 0.133 & $(0.034)$ & 0.029 & $(0.028)$ & 0.072 & $(0.035)$ \\
\hline $3^{\text {rd }}$ Wealth quartile & 0.258 & $(0.036)$ & 0.027 & $(0.030)$ & 0.123 & $(0.036)$ \\
\hline $4^{\text {th }}$ Wealth quartile & 0.336 & $(0.039)$ & -0.014 & $(0.033)$ & 0.271 & (0.039) \\
\hline Urban & -0.090 & $(0.046)$ & 0.197 & $(0.037)$ & 0.478 & $(0.046)$ \\
\hline Microfinance & 0.313 & $(0.023)$ & & & & \\
\hline Year 2005/06 & & & 0.395 & $(0.030)$ & -0.670 & $(0.039)$ \\
\hline Year 2010/11 & 1.459 & $(0.027)$ & 0.674 & $(0.045)$ & 0.085 & $(0.045)$ \\
\hline Covariance & & & -0.281 & $(0.044)$ & 0.886 & $(0.013)$ \\
\hline Variance & & & & & 1.706 & $(0.024)$ \\
\hline District dummies & Yes & & Yes & & Yes & \\
\hline \multicolumn{7}{|c|}{ Predicted expenditure (2000 prices) } \\
\hline Whole sample & 2,312 & $(41)$ & & & & \\
\hline Insured & 1,410 & $(28)$ & & & & \\
\hline Uninsured & 5,019 & $(226)$ & & & & \\
\hline No. of obs. & 26,243 & & 26,243 & & 26,243 & \\
\hline
\end{tabular}


Table 5. Outpatient Expenditure: ETPM Posterior Means and Standard Deviations

\begin{tabular}{|c|c|c|c|c|c|c|}
\hline & \multicolumn{2}{|c|}{$\mathrm{CBHI}$} & \multicolumn{2}{|c|}{ Hurdle } & \multicolumn{2}{|c|}{ Expenditure } \\
\hline & Mean & Std.Dev. & Mean & Std.Dev. & Mean & Std.Dev. \\
\hline Intercept & -1.636 & $(0.078)$ & -1.651 & $(0.081)$ & 8.067 & $(0.095)$ \\
\hline $\mathrm{CBHI}$ & & & 1.072 & $(0.162)$ & -0.188 & $(0.114)$ \\
\hline Head: age & 0.005 & (0.001) & -0.005 & $(0.001)$ & 0.002 & $(0.001)$ \\
\hline Head: male & -0.335 & $(0.027)$ & 0.067 & $(0.030)$ & 0.052 & $(0.035)$ \\
\hline Head: married & 0.570 & $(0.024)$ & -0.076 & $(0.035)$ & -0.066 & $(0.035)$ \\
\hline $\mathrm{HH}$ : size & -0.015 & $(0.005)$ & 0.013 & $(0.005)$ & -0.191 & $(0.006)$ \\
\hline HH: No. of individuals w/ illness & -0.070 & $(0.009)$ & 0.238 & $(0.011)$ & 0.105 & $(0.010)$ \\
\hline Head educ.: primary & 0.295 & $(0.021)$ & 0.032 & $(0.023)$ & -0.043 & $(0.027)$ \\
\hline Head edu.: sec/voc/univ & 0.493 & $(0.042)$ & 0.086 & $(0.044)$ & 0.232 & $(0.046)$ \\
\hline \# of wage earner & -0.009 & $(0.008)$ & 0.024 & $(0.008)$ & & \\
\hline $2^{\text {nd }}$ cons. quartile & 0.103 & $(0.027)$ & 0.151 & $(0.027)$ & 0.163 & $(0.032)$ \\
\hline $3^{\text {rd }}$ cons. quartile & 0.154 & $(0.029)$ & 0.298 & $(0.029)$ & 0.300 & $(0.035)$ \\
\hline $4^{\text {th }}$ cons. quartile & 0.281 & $(0.035)$ & 0.467 & $(0.033)$ & 0.778 & $(0.040)$ \\
\hline $2^{\text {nd }}$ wealth quartile & 0.147 & $(0.026)$ & 0.029 & $(0.027)$ & 0.040 & $(0.032)$ \\
\hline $3^{\text {rd }}$ wealth quartile & 0.268 & $(0.027)$ & 0.018 & $(0.030)$ & 0.013 & $(0.034)$ \\
\hline $4^{\text {th }}$ wealth quartile & 0.357 & $(0.031)$ & 0.039 & $(0.032)$ & 0.167 & $(0.038)$ \\
\hline Urban & -0.070 & $(0.037)$ & 0.149 & $(0.035)$ & 0.441 & $(0.041)$ \\
\hline Microfinance & 0.386 & $(0.023)$ & & & & \\
\hline Year 2005/06 & & & 1.001 & $(0.037)$ & -2.147 & $(0.049)$ \\
\hline Year 2010/11 & 1.501 & $(0.022)$ & 0.679 & $(0.064)$ & -2.573 & $(0.064)$ \\
\hline Covariance & & & -0.404 & $(0.092)$ & -0.058 & $(0.063)$ \\
\hline Variance & & & & & 1.423 & $(0.019)$ \\
\hline District dummies & Yes & & Yes & & Yes & \\
\hline \multicolumn{7}{|c|}{ Predicted expenditure (2000 prices) } \\
\hline Whole sample & 385 & (12) & & & & \\
\hline Insured & 689 & $(85)$ & & & & \\
\hline Uninsured & 343 & (14) & & & & \\
\hline No. of obs. & 26,243 & & 26,243 & & 26,243 & \\
\hline
\end{tabular}


Table 6. Inpatient Expenditure: ETPM Posterior Means and Standard Deviations

\begin{tabular}{|c|c|c|c|c|c|c|}
\hline & \multicolumn{2}{|c|}{$\mathrm{CBHI}$} & \multicolumn{2}{|c|}{ Hurdle } & \multicolumn{2}{|c|}{ Expenditure } \\
\hline & Mean & Std.Dev. & Mean & Std.Dev. & Mean & Std.Dev. \\
\hline Intercept & -1.637 & $(0.071)$ & -2.488 & $(0.098)$ & 9.080 & $(0.263)$ \\
\hline $\mathrm{CBHI}$ & & & 0.334 & $(0.146)$ & -0.269 & $(0.297)$ \\
\hline Head: age & 0.005 & (0.001) & -0.005 & $(0.001)$ & 0.008 & $(0.002)$ \\
\hline Head: male & -0.338 & $(0.027)$ & 0.030 & $(0.039)$ & 0.108 & $(0.102)$ \\
\hline Head: married & 0.573 & $(0.023)$ & 0.027 & $(0.040)$ & -0.162 & $(0.095)$ \\
\hline $\mathrm{HH}:$ size & -0.015 & $(0.005)$ & 0.013 & $(0.006)$ & -0.163 & $(0.015)$ \\
\hline $\mathrm{HH}$ : \# of individuals w/illness & -0.065 & $(0.008)$ & 0.102 & $(0.010)$ & -0.020 & $(0.026)$ \\
\hline Head educ.: primary & 0.295 & $(0.020)$ & 0.022 & $(0.031)$ & 0.003 & $(0.082)$ \\
\hline Head edu.: sec/voc/univ & 0.492 & $(0.040)$ & -0.012 & $(0.052)$ & 0.004 & $(0.134)$ \\
\hline \# of wage earner & -0.010 & $(0.008)$ & 0.023 & $(0.010)$ & & \\
\hline $2^{\text {nd }}$ cons. quartile & 0.110 & $(0.025)$ & 0.170 & $(0.037)$ & 0.188 & $(0.100)$ \\
\hline $3^{\text {rd }}$ cons. quartile & 0.162 & $(0.028)$ & 0.293 & $(0.039)$ & 0.353 & $(0.106)$ \\
\hline $4^{\text {th }}$ cons. quartile & 0.293 & $(0.032)$ & 0.470 & $(0.044)$ & 0.892 & $(0.117)$ \\
\hline $2^{\text {nd }}$ wealth quartile & 0.138 & $(0.026)$ & -0.027 & $(0.035)$ & -0.116 & $(0.087)$ \\
\hline $3^{\text {rd }}$ wealth quartile & 0.260 & $(0.027)$ & -0.037 & $(0.039)$ & -0.196 & $(0.093)$ \\
\hline $4^{\text {th }}$ wealth quartile & 0.340 & $(0.030)$ & -0.100 & $(0.044)$ & -0.004 & $(0.116)$ \\
\hline Urban & -0.067 & $(0.034)$ & 0.085 & $(0.045)$ & 0.471 & $(0.112)$ \\
\hline Microfinance & 0.379 & $(0.023)$ & & & & \\
\hline Year 2005/06 & & & 1.092 & (0.047) & -2.298 & $(0.141)$ \\
\hline Year 2010/11 & 1.503 & $(0.021)$ & 0.424 & $(0.087)$ & -3.050 & $(0.187)$ \\
\hline Covariance & & & -0.064 & $(0.084)$ & -0.010 & $(0.164)$ \\
\hline Variance & & & & & 2.158 & $(0.066)$ \\
\hline District dummies & Yes & & Yes & & Yes & \\
\hline \multicolumn{7}{|c|}{ Predicted expenditure (2000 prices) } \\
\hline Whole sample & 304 & $(27)$ & & & & \\
\hline Insured & 432 & (139) & & & & \\
\hline Uninsured & 291 & $(40)$ & & & & \\
\hline No. of obs. & 26,243 & & 26,243 & & 26,243 & \\
\hline
\end{tabular}


Table 7. Drug Expenditure: ETPM Posterior Means and Standard Deviations

\begin{tabular}{|c|c|c|c|c|c|c|}
\hline & \multicolumn{2}{|c|}{$\mathrm{CBHI}$} & \multicolumn{2}{|c|}{ Hurdle } & \multicolumn{2}{|c|}{ Expenditure } \\
\hline & Mean & Std.Dev. & Mean & Std.Dev. & Mean & Std.Dev. \\
\hline Intercept & -1.620 & $(0.080)$ & -0.470 & $(0.067)$ & 6.761 & $(0.145)$ \\
\hline $\mathrm{CBHI}$ & & & 0.031 & $(0.153)$ & -1.941 & $(0.057)$ \\
\hline Head: age & 0.005 & $(0.001)$ & -0.007 & $(0.001)$ & 0.014 & $(0.001)$ \\
\hline Head: male & -0.343 & $(0.028)$ & 0.080 & $(0.029)$ & -0.224 & $(0.052)$ \\
\hline Head: married & 0.570 & $(0.026)$ & -0.045 & $(0.035)$ & 0.070 & $(0.049)$ \\
\hline $\mathrm{HH}:$ Size & -0.015 & $(0.006)$ & 0.016 & $(0.005)$ & -0.272 & $(0.010)$ \\
\hline $\mathrm{HH}$ : \# of individuals w/ illness & -0.058 & $(0.010)$ & 0.344 & $(0.010)$ & 0.391 & $(0.018)$ \\
\hline Head educ.: primary & 0.302 & $(0.023)$ & -0.023 & $(0.026)$ & 0.231 & $(0.047)$ \\
\hline Head edu.: sec/voc/univ & 0.497 & $(0.045)$ & 0.031 & $(0.045)$ & 0.479 & $(0.077)$ \\
\hline No. of wage earner & -0.012 & $(0.008)$ & -0.007 & $(0.008)$ & & \\
\hline $2^{\text {nd }}$ cons. quartile & 0.115 & $(0.028)$ & 0.255 & $(0.028)$ & 0.440 & $(0.069)$ \\
\hline $3^{\text {rd }}$ cons. quartile & 0.177 & $(0.030)$ & 0.425 & $(0.029)$ & 0.842 & $(0.069)$ \\
\hline $4^{\text {th }}$ cons. quartile & 0.303 & $(0.038)$ & 0.654 & $(0.034)$ & 1.560 & $(0.076)$ \\
\hline $2^{\text {nd }}$ wealth quartile & 0.132 & $(0.028)$ & -0.055 & $(0.027)$ & -0.135 & $(0.057)$ \\
\hline $3^{\text {rd }}$ wealth quartile & 0.253 & $(0.030)$ & -0.143 & $(0.030)$ & -0.151 & $(0.060)$ \\
\hline $4^{\text {th }}$ wealth quartile & 0.333 & $(0.033)$ & -0.135 & $(0.033)$ & -0.014 & $(0.057)$ \\
\hline Urban & -0.073 & $(0.039)$ & 0.276 & $(0.033)$ & 0.347 & $(0.071)$ \\
\hline Microfinance & 0.336 & $(0.025)$ & & & & \\
\hline Year 2005/06 & & & -0.056 & $(0.028)$ & -0.050 & $(0.055)$ \\
\hline Year 2010/11 & 1.495 & $(0.023)$ & -0.700 & $(0.083)$ & 0.460 & $(0.066)$ \\
\hline Covariance & & & -0.126 & 0.090 & 0.886 & $(0.014)$ \\
\hline Variance & & & & & 2.366 & $(0.049)$ \\
\hline District dummies & Yes & & Yes & & Yes & \\
\hline \multicolumn{7}{|c|}{ Predicted expenditure (2000 prices) } \\
\hline Whole sample & 1,855 & $(64)$ & & & & \\
\hline Insured & 612 & $(35)$ & & & & \\
\hline Uninsured & 4,166 & (469) & & & & \\
\hline No. of obs. & 26,243 & & 26,243 & & 26,243 & \\
\hline
\end{tabular}


Table 8. Overall Healthcare Expenditure Net of Premium: ETPM Posterior Means and Standard Deviations

\begin{tabular}{|c|c|c|c|c|c|c|}
\hline & \multicolumn{2}{|c|}{$\mathrm{CBHI}$} & \multicolumn{2}{|c|}{ Hurdle } & \multicolumn{2}{|c|}{ Expenditure } \\
\hline & Mean & Std.Dev. & Mean & Std.Dev. & Mean & Std.Dev. \\
\hline Intercept & -1.650 & $(0.089)$ & -0.713 & $(0.073)$ & 7.189 & $(0.116)$ \\
\hline $\mathrm{CBHI}$ & & & 0.948 & $(0.115)$ & -1.959 & $(0.034)$ \\
\hline Head: age & 0.006 & (0.001) & -0.008 & $(0.001)$ & 0.006 & $(0.001)$ \\
\hline Head: male & -0.345 & $(0.032)$ & 0.106 & $(0.028)$ & -0.116 & $(0.041)$ \\
\hline Head: married & 0.567 & $(0.030)$ & -0.043 & $(0.029)$ & 0.120 & $(0.038)$ \\
\hline $\mathrm{HH}:$ size & -0.017 & $(0.006)$ & 0.026 & $(0.005)$ & -0.239 & $(0.007)$ \\
\hline $\mathrm{HH}$ : \# of individuals w/ illness & -0.059 & $(0.011)$ & 0.372 & $(0.012)$ & 0.344 & $(0.013)$ \\
\hline Head educ.: primary & 0.306 & $(0.025)$ & 0.006 & $(0.022)$ & 0.188 & $(0.034)$ \\
\hline Head edu.: sec/voc/univ & 0.508 & $(0.051)$ & 0.006 & $(0.045)$ & 0.460 & $(0.061)$ \\
\hline No. of wage earner & -0.011 & $(0.008)$ & 0.020 & $(0.008)$ & & \\
\hline $2^{\text {nd }}$ cons. quartile & 0.112 & $(0.031)$ & 0.211 & $(0.026)$ & 0.411 & $(0.044)$ \\
\hline $3^{\text {rd }}$ cons. quartile & 0.177 & $(0.034)$ & 0.379 & $(0.028)$ & 0.826 & $(0.047)$ \\
\hline $4^{\text {th }}$ cons. quartile & 0.319 & $(0.041)$ & 0.593 & $(0.033)$ & 1.672 & $(0.053)$ \\
\hline $2^{\text {nd }}$ wealth quartile & 0.140 & $(0.032)$ & -0.022 & $(0.026)$ & 0.042 & $(0.043)$ \\
\hline $3^{\text {rd }}$ wealth quartile & 0.265 & $(0.033)$ & -0.063 & $(0.029)$ & 0.041 & $(0.043)$ \\
\hline $4^{\text {th }}$ wealth quartile & 0.349 & $(0.037)$ & -0.093 & $(0.032)$ & 0.238 & $(0.047)$ \\
\hline Urban & -0.081 & $(0.044)$ & 0.231 & $(0.036)$ & 0.512 & $(0.054)$ \\
\hline Microfinance & 0.324 & $(0.024)$ & & & & \\
\hline Year 2005/06 & & & 0.558 & $(0.029)$ & -0.432 & $(0.048)$ \\
\hline Year 2010/11 & 1.494 & $(0.026)$ & 0.118 & $(0.059)$ & -0.379 & $(0.052)$ \\
\hline Covariance & & & -0.361 & $(0.064)$ & 0.894 & $(0.006)$ \\
\hline Variance & & & & & 2.463 & $(0.033)$ \\
\hline District dummies & Yes & & Yes & & Yes & \\
\hline \multicolumn{7}{|c|}{ Predicted expenditure (2000 prices) } \\
\hline Whole sample & 2,737 & (75) & & & & \\
\hline Insured & 1,140 & (36) & & & & \\
\hline Uninsured & 5,246 & (314) & & & & \\
\hline No. of obs. & 26,243 & & 26,243 & & 26,243 & \\
\hline
\end{tabular}


Table 9. Average Treatment Effects on the Probability and the Amount of Healthcare Spending

(RWF: In 2000 Prices)

Table 10. Sensitivity Analysis I: Sensitivity to Different Prior Selections (2000 prices)

\begin{tabular}{lcccc}
\hline & \multicolumn{4}{c}{ Prior Selection } \\
\cline { 2 - 5 } & 2 & 1 & $1 / 5$ & $1 / 8$ \\
\hline ATE on the probability of spending & 0.317 & 0.317 & 0.315 & 0.317 \\
& $(0.016)$ & $(0.017)$ & $(0.017)$ & $(0.018)$ \\
ATE on the amount of spending (RWF) & $-3,624$ & $-3,625$ & $-3,639$ & $-3,605$ \\
& $(215)$ & $(221)$ & $(222)$ & $(231)$ \\
& & & & \\
Covariance w/hurdle part & -0.2783 & -0.280 & -0.2734 & -0.2794 \\
Covariance w/expenditure part & $(0.038)$ & $(0.041)$ & $(0.040)$ & $(0.044)$ \\
& 0.8863 & 0.8866 & 0.8855 & 0.8841 \\
Variance & $(0.014)$ & $(0.013)$ & $(0.014)$ & $(0.015)$ \\
& 1.707 & 1.7073 & 1.7079 & 1.7091 \\
Bayes Factor & $(0.024)$ & $(0.024)$ & $(0.026)$ & $(0.026)$ \\
\hline
\end{tabular}




\section{Appendix A. Estimation Algorithm of Two-Part Model with Binary Selection}

\begin{tabular}{ll} 
& \multicolumn{1}{c}{ Box 1. Estimation Algorithm } \\
\hline Step 1: & draw the latent variable $d_{i}^{*}$ from its conditional truncated normal distribution \\
Step 2: & draw the latent variable $s_{i}^{*}$ from its conditional truncated normal distribution \\
Step 3: & for $i=1, \ldots, n<N$ such that $s_{i}=0$, draw the latent variable $m_{i}^{*}$ from its conditional \\
& normal distribution, otherwise set $y_{i}^{*}=\ln \left(y_{i}\right)$. \\
Step 4: & draw $\beta^{d}$ for its conditional normal distribution \\
Step 5: & draw $\theta^{s}=\left[\beta^{d}, \gamma^{s}\right]$ from the joint conditional normal distribution \\
Step 6: & Draw $\sigma_{d s}$ from the conditional truncated normal distribution \\
Step 7: & draw $\theta^{m}=\left[\beta^{m}, \gamma^{m}\right]$ from the joint conditional normal distribution \\
Step 8: & Draw $\sigma_{d m}$ from the conditional normal distribution \\
Step 9: & draw $\sigma_{m}^{-2}$ from the conditional gamma distribution \\
\hline
\end{tabular}

1. For $i=1, \ldots, N$, draw the latent variable $d_{i}^{*}$ from its conditional truncated normal distribution given by

$$
d_{i}^{*} \mid \cdot \sim\left\{\begin{array}{cc}
T N_{(-\infty, 0]}\left(\mu_{d}, V_{d}\right) & \text { if } d_{i}=0 \\
T N_{(0, \infty)}\left(\mu_{d}, V_{d}\right) & \text { if } d_{i}=1
\end{array}\right.
$$

where $\mu_{d}=\beta^{d} w_{i}+V_{d}\left[\sigma_{d s}\left(s_{i}^{*}-\beta^{s} x_{i}-\gamma^{s} d_{i}\right)+\frac{\sigma_{d m}}{\sigma_{m}^{2}}\left(m_{i}^{*}-\beta^{m} x_{i}-\gamma^{m} d_{i}\right)\right]$, and $V_{d}=\left(1+\sigma_{d s}^{2}+\frac{\sigma_{d m}^{2}}{\sigma_{m}^{2}}\right)^{-1}$

2. For $i=1, \ldots, N$, draw the latent variable $m_{i}^{*}$ from its conditional truncated normal distribution given by

$$
s_{i}^{*} \mid \cdot \sim \begin{cases}T N_{(-\infty, 0]}\left(\mu_{s}, 1\right) & \text { if } s_{i}=0 \\ T N_{(0, \infty)}\left(\mu_{s}, 1\right) & \text { if } s_{i}=1\end{cases}
$$

where $\mu_{s}=\beta^{s} x_{i}+\gamma^{s} d_{i}+\sigma_{d s} \varepsilon_{i}^{d}$.

3. For $i=1, \ldots, n<N$ such that $s_{i}=0$, draw the latent variable $m_{i}^{*}$ from its conditional normal distribution given by

where $\mu_{m}=\beta^{m} x_{i}+\gamma^{m} d_{i}+\sigma_{d m} \varepsilon_{i}^{d}$.

$$
m_{i}^{*} \mid \cdot \sim \begin{cases}N\left(\mu_{m}, \sigma_{m}^{2}\right) & \text { if } s_{i}=0 \\ m & \text { if } s_{i}=1\end{cases}
$$

4. Draw $\beta^{d}$ from its conditional normal distribution given by

$$
\beta^{d} \mid \cdot \sim N\left(\mu_{\left.\beta^{d}, V_{\beta^{d}}\right),}\right.
$$


where $\mu_{\beta^{d}}=V_{\beta^{d}}\left[V_{0} \mu_{0}+\sum_{i=1}^{N} w_{i}^{\prime}\left\{\frac{d_{i}^{*}}{\left(1+\sigma_{d s}^{2}+\frac{\sigma_{d m}^{2}}{\sigma_{m}^{2}}\right)}-\sigma_{d s}\left(s_{i}^{*}-\beta^{s} x_{i}-\gamma^{s} d_{i}\right)-\right.\right.$
$\left.\left.\frac{\sigma_{d m}}{\sigma_{m}^{2}}\left(m_{i}^{*}-\beta^{m} x_{i}-\gamma^{m} d_{i}\right)\right\}\right]$, and $V_{\beta^{d}}=\left[V_{0}+\sum_{i=1}^{N} \frac{w_{i} w_{i}^{\prime}}{\left(1+\sigma_{d s}^{2}+\frac{\sigma_{d m}^{2}}{\sigma_{m}^{2}}\right)}\right]$.

5. Draw $\theta^{h}=\left[\beta^{d}, \gamma^{h}\right]$ from the joint conditional normal distribution given by $\theta^{h} \mid \cdot \sim N\left(\mu_{\theta^{h}}, V_{\theta^{h}}\right)$

where $\mu_{\theta^{s}}=V_{\theta^{s}}\left[\left(\begin{array}{c}V_{0} \mu_{0} \\ V_{\gamma_{0}} \mu_{\gamma_{0}}\end{array}\right)+\sum_{i=1}^{N} X_{i}^{\prime}\left(s_{i}^{*}-\sigma_{d s} \varepsilon_{i}^{d}\right)\right]$ and

$V_{\theta^{s}}=\left[\begin{array}{cc}V_{0} & 0 \\ 0 & V_{\gamma_{0}}\end{array}\right]+\sum_{i=1}^{N} X_{i}^{\prime} X_{i}$

6. Draw $\sigma_{d s}$ from the conditional truncated normal distribution

$$
\sigma_{d h} \mid . \sim T N_{[-0.9,0.9]}\left(\mu_{\sigma_{d s}}, V_{\sigma_{d s}}\right) \text {, }
$$

where $\mu_{\sigma_{d s}}=V_{\sigma_{d s}}\left(V_{\sigma_{0}} \mu_{\sigma_{0}}+\sum_{i=1}^{N} \varepsilon_{i}^{d}\left(s_{i}^{*}-\beta^{s} x_{i}-\gamma^{s} d_{i}\right)\right)$ and $V_{\sigma_{d s}}=\left[V_{\sigma_{0}}+\right.$ $\left.\sum_{i=1}^{N} \varepsilon_{i}^{d \prime} \varepsilon_{i}^{d}\right]$.

7. Draw $\theta^{m}=\left[\beta^{m}, \gamma^{m}\right]$ from the joint conditional normal distribution given by $\theta^{m} \mid \cdot \sim N\left(\mu_{\theta^{m}}, V_{\theta^{m}}\right)$, where $\mu_{\theta^{m}}=V_{\theta^{m}}\left[\left(\begin{array}{c}V_{0} \mu_{0} \\ V_{\gamma_{0}} \mu_{\gamma_{0}}\end{array}\right)+\sum_{i=1}^{N} X_{i}^{\prime} \sigma_{m}^{-2}\left(m_{i}^{*}-\sigma_{d m} \varepsilon_{i}^{d}\right)\right]$ and $V_{\theta^{m}}=\left[\begin{array}{cc}V_{0} & 0 \\ 0 & V_{\gamma_{0}}\end{array}\right]+$ $\sum_{i=1}^{N} X_{i}^{\prime} \sigma_{y}^{-2} X_{i}$

8. Draw $\sigma_{d m}$ from the conditional truncated normal distribution

$$
\sigma_{d m} \mid . \sim T N_{[-0.9,0.9]}\left(\mu_{\sigma_{d m}}, V_{\sigma_{d m}}\right) \text {, }
$$

where $\mu_{\sigma_{d m}}=V_{\sigma_{d m}}\left(V_{\sigma_{0}} \mu_{\sigma_{0}}+\sum_{i=1}^{N} \varepsilon_{i}^{d}\left(m_{i}^{*}-\beta^{m} x_{i}-\gamma^{m} d_{i}\right)\right)$ and $V_{\sigma_{d m}}=$ $\left[V_{\sigma_{0}}+\sum_{i=1}^{N} \frac{\varepsilon_{i}^{d \prime} \varepsilon_{i}^{d}}{\sigma_{m}^{2}}\right]$.

9. Draw $\sigma_{m}^{-2}$ from the conditional gamma distribution given by

$$
\sigma_{m}^{-2} \sim g\left(\frac{v+N}{2},\left[\frac{c}{2}+\sum_{i=1}^{N} \frac{\left(m_{i}^{*}-\beta^{m} x_{i}-\gamma^{m} d_{i}-\sigma_{d m} \varepsilon_{i}^{d}\right)^{2}}{2}\right]^{-1}\right)
$$

Cycling through steps 1--9 until convergence provides the posterior parameter estimates. We wrote the estimation code in Matlab and tested on simulated data before we apply it to the real data. We conduct 10,000 MCMC simulations with the first 5,000 draws dropped as burnins. Convergence of the MCMC draws are assessed using trace plots as well as formal convergence diagnostic test developed by Geweke (1992). 


\section{Appendix B. Additional Table}

Table B.1: Covariate Balancing Test

\begin{tabular}{|c|c|c|c|c|c|}
\hline \multirow[b]{2}{*}{ Variable } & \multicolumn{2}{|c|}{ Microfinance } & \multirow[b]{2}{*}{ \%bias } & \multirow[b]{2}{*}{$\mathrm{t}$} & \multirow[b]{2}{*}{$p>t$} \\
\hline & Member & Non-Member & & & \\
\hline $\mathrm{HHAgeHH}$ & 44.325 & 44.521 & -1.3 & -0.71 & 0.479 \\
\hline HHSize & 5.410 & 5.409 & 0.1 & 0.03 & 0.975 \\
\hline HHAge & 22.629 & 22.758 & -1.2 & -0.71 & 0.476 \\
\hline HHmale & 0.775 & 0.770 & 1.1 & 0.58 & 0.56 \\
\hline HHmarried & 0.645 & 0.641 & 0.8 & 0.45 & 0.655 \\
\hline HHIllness & 1.021 & 1.021 & 0 & -0.02 & 0.987 \\
\hline AlcoholUse & 0.405 & 0.398 & 1.5 & 0.79 & 0.43 \\
\hline CigaretteUse & 0.182 & 0.183 & -0.3 & -0.16 & 0.875 \\
\hline HHU5 & 0.988 & 0.981 & 0.8 & 0.42 & 0.672 \\
\hline HHElderly & 0.131 & 0.136 & -1.3 & -0.69 & 0.49 \\
\hline HHChild & 2.004 & 1.999 & 0.3 & 0.15 & 0.879 \\
\hline FirstConsQuart & 0.160 & 0.162 & -0.6 & -0.35 & 0.728 \\
\hline SeconConsQuart & 0.241 & 0.235 & 1.3 & 0.7 & 0.486 \\
\hline ThirdConsQuart & 0.306 & 0.302 & 0.7 & 0.36 & 0.721 \\
\hline FourtConsQuart & 0.293 & 0.300 & -1.4 & -0.71 & 0.475 \\
\hline FirstWealthQuart & 0.175 & 0.182 & -1.6 & -0.91 & 0.36 \\
\hline SeconWealthQuart & 0.239 & 0.236 & 0.6 & 0.32 & 0.751 \\
\hline ThirdWealthQuart & 0.297 & 0.296 & 0.1 & 0.07 & 0.942 \\
\hline FourtWealthQuart & 0.289 & 0.286 & 0.8 & 0.4 & 0.688 \\
\hline HeadPrimary & 0.588 & 0.584 & 1 & 0.51 & 0.608 \\
\hline HeadSecVocUniv & 0.092 & 0.095 & -1.1 & -0.51 & 0.613 \\
\hline HeadNoEduc & 0.253 & 0.254 & -0.2 & -0.11 & 0.909 \\
\hline WageEarner & 1.119 & 1.134 & -1.2 & -0.61 & 0.541 \\
\hline Urban & 0.131 & 0.140 & -2.5 & -1.41 & 0.158 \\
\hline Number of obs. & 5,486 & 20,757 & & & \\
\hline
\end{tabular}

CInternational Monetary Fund. Not for Redistribution 


\section{References}

Acharya, A., Vellakkal, S., Taylor, F., Masset, E., Satija, A., Burke, M., \& Ebrahim, S., 2012, The Impact of Health Insurance Schemes for the Informal Sector in Low- and Middle-Income Countries: A Systematic Review (The World Bank Research Observer, 1ks009).

Austin, P.C., 2009, "Balance Diagnostics for Comparing the Distribution of Baseline Covariates Between Treatment Groups in Propensity Score Matched Samples," Statistics in Medicine, Vol. 28, No. 25, pp. 3083-3107.

Albert, J. and Chib S., 1991, Bayesian Analysis of Binary and Polychotomous Response Data, Technical Report (Bowling Green State University, Department of Mathematics).

Bajari, P., Hong, H. and Khwaja, A., 2006, "Moral Hazard, Adverse Selection and Health Expenditures: A Semiparametric Analysis,” NBER Working Paper 12445 (Cambridge: National Bureau of Economic Research).

Bolhaar, J., Lindeboom, M., \& van der Klaauw, B., 2012, A Dynamic Analysis of the Demand for Health Insurance and Health Care, European Economic Review, Vol. 56, No. 4, pp. 669-90.

Brown, J.R. and Finkelstein, A., 2008, "The Interaction of Public and Private Insurance: Medicaid and the Long-Term Care Insurance Market," American Economic Review, Vol. 98, p.1083-1102.

Cragg, J. G., 1971, Some Statistical Models for Limited Dependent Variables with Application to the Demand for Durable Goods. Econometrica: Journal of the Econometric Society, pp. 829-44.

De Weerdt, J. and S. Dercon, 2006, Risk-Sharing Networks and Insurance Against Illness, Journal of Development Economics, Vol. 81, No. 2, pp. 337-56.

Deb, P., Munkin, M. K., \& Trivedi, P. K., 2006, Bayesian Analysis of the Two-Part Model with Endogeneity: Application to Health Care Expenditure, Journal of Applied Econometrics, Vol. 21, No. 7, pp. 1081-99.

Dercon, S. and P. Krishnan, 2000, In Sickness and In Health: Risk Sharing Within Households in Rural Ethiopia, Journal of Political Economy, Vol. 108, No. 4, pp. 688-727.

Diop, P., Butera, \& Damascene, J., 2005, Community-Based Health Insurance in Rwanda. Available on the internet https://openknowledge.worldbank.org/handle/10986/9650 License: CC BY 3.0 Unported. 
Ekman, B., 2004, Community-Based Health Insurance in Low-Income Countries: A Systematic Review of the Evidence, Health Policy and Planning, Vol. 19, No. 5, pp. 249-70.

Escobar, M. L., Griffin, C. C., \& Shaw, R. P., eds., 2011, The Impact of Health Insurance in Low- and Middle-Income Countries (Washington: Brookings Institution Press).

Fafchamps, M. and S. Lund (2003). Risk-Sharing Networks in Rural Philippines, Journal of Development Economics, Vol. 71, No. 2, pp. 261-87.

Galárraga, O., Sosa-Rubí, S. G., Salinas-Rodríguez, A., \& Sesma-Vázquez, S., 2010, Health Insurance for the Poor: Impact on Catastrophic and Out-Of-Pocket Health Expenditures in Mexico, European Journal of Health Economics, Vol. 11, No. 5, pp. 437-47.

Geweke, J., 1992, "Evaluating the Accuracy of Sampling-Based Approaches to the Calculation of Posterior Moments," in Bayesian Statistics 4, ed. by J.O. Berger, A.P. Dawid, and A.F.M. Smith (Oxford: Oxford University Press).

Giedion, U., Andrés Alfonso, E., \& Díaz, Y., 2013, The Impact of Universal Coverage Schemes in the Developing World: A Review of the Existing Evidence, Universal Health Coverage Studies Series (UNICO) UNICO Studies Series No. 25.

Gnawali, D.P., S. Pokhrel, A. Sie', M. Sanon, M. De Allegri, A. Souares, H. Dong, and R. Sauerborn, 2009, The Effect of Community-Based Health Insurance on the Utilization of Modern Health Care Services: Evidence from Burkina Faso, Health Policy, Vol. 90, No. 2-3, pp. 214-22.

Jakab, M., \& Krishnan, C., 2001, Community Involvement in Health Care Financing: Impact, Strengths and Weaknesses: A Synthesis of Literature (Washington: World Bank).

Jütting, J. P., 2004, Do Community-Based Health Insurance Schemes Improve Poor People's Access to Health Care? Evidence from Rural Senegal, World Development, Vol. 32, No. 2, pp. 273-88.

Keane, M., \& Stavrunova, O., 2011, Adverse Selection, Moral Hazard and the Demand for Medigap Insurance, School of Finance and Economics (Sydney: University of Technology Sydney). Unpublished Manuscript.

Keane, M., \& Stavrunova, O., 2011, Adverse Selection, Moral Hazard and the Demand for Medigap Insurance, School of Finance and Economics.

Leive, A., \& Xu, K., 2008, Coping with Out-of-Pocket Health Payments: Empirical Evidence From 15 African Countries. Bulletin of the World Health Organization, 
Vol. 86, No. 11, pp. 849-56C.

Li Qian, and Trivedi Pravin K., 2014, Adverse and Advantageous Selection in The Medicare Supplemental Market: A Bayesian Analysis Of Prescription Drug Expenditure, Health Econ., doi: 10.1002/hec.3133.

Li, M. and J. L. Tobias, 2008, Bayesian Analysis of Treatment Effects in An Ordered Potential Outcomes Model. Advances in Econometrics, Vol. 21, pp. 57-91.

Long, Q., Zhang, Y., Raven, J., Wu, Z., Bogg, L., Tang, S., \& Hemminki, E., 2011, Giving Birth at A Health-Care Facility in Rural China: Is It Affordablefor the Poor? Bulletin of the World Health Organization, Vol. 89, No. 2, pp. 144-152.

Lu, C., B. Chin, J.L. Lewandowski, P. Basinga, L.R. Hirschhorn, 2012, Towards Universal Health Coverage: An Evaluation of Rwanda Mutuelles in Its First Eight Years, PLoS ONE Vol. 7, No. 6, e39282. doi:10.1371/journal.pone.0039282

Manning, W. G., Duan, N., \& Rogers, W. H., 1987, Monte Carlo Evidence on the Choice Between Sample Selection and Two-Part Models. Journal of econometrics, Vol. 35, No. 1, pp. 59-82.

Manning, W. G., Morris, C. N., Newhouse, J. P., Orr, L. L., Duan, N., Keeler, E. B., \& Phelps, C. E., 1981, A Two-Part Model of The Demand for Medical Care: Preliminary Results from the Health Insurance Study, Health, Economics, And Health Economics, pp. 103-23.

Mebratie, A., Sparrow, R., Yilma, Z., Abebaw, D., Alemu, G. and Bedi, A.S., 2013, Impact of Ethiopian Pilot Community Based Health Insurance Scheme on Health Care Utilization: A Household Panel Data Analysis. The Lancet. 381: S92

Mensah, J., J. Oppong, and C. Schmidt, 2010, An Evaluation of the Ghana National Health Insurance Scheme in the Context of The Health MDGs, Health Economics, Vol. 19, No. S1, pp. 95-106.

MoH, 2010, Rwanda National Health Insurance Policy. Republic of Rwanda, Ministry of Health, December 2010.

MoH, 2011, Ministry of Health Annual Report. Republic of Rwanda, Ministry of Health. Kigali.

Munkin, M. K. and Trivedi, P. K., 2010, Disentangling Incentives Effects of Insurance Coverage from Adverse Selection in the Case of Drug Expenditure: A Finite Mixture Approach, Health Econ., Vol. 19, pp. 1093-1108. doi: 10.1002/hec.1636.

Nguyen, H. T., Rajkotia, Y., \& Wang, H., 2011, The Financial Protection Effect of 
Ghana National Health Insurance Scheme: Evidence from a Study in Two Rural Districts. International Journal of Equity Health, Vol. 10, No. 4, pp. 9-10.

O'Donnell, O. A., \& Wagstaff, A., 2008, Analyzing Health Equity Using Household Survey Data: A Guide to Techniques and Their Implementation (Washington: World Bank Publications).

Schneider, P., \& Diop, F., 2001, Synopsis of Results on the Impact of Community-Based Health Insurance on Financial Accessibility to Health Care in Rwanda (Washington: World Bank).

Shimeles, A., 2010, Community-Based Health Insurance Schemes in Africa: The Case of Rwanda, Working Papers Series No. 120, African Development Bank, Tunis, Tunisia.

Tanner, M. A. and W. H. Wong, 1987, The Calculation of Posterior Distributions by Data Augmentation, Journal of the American Statistical Association, Vol. 82, No. 398, pp. $528-40$.

Trivedi, P., 2002, Patterns of Health Care Utilization in Vietnam, World Bank Policy Research Working Paper (Washington DC: World Bank).

Umeh, C. A., \& Feeley, F. G., 2017, Inequitable Access to Health Care by the Poor in Community-Based Health Insurance Programs: A Review of Studies from Low- and Middle-Income Countries, Global Health: Science and Practice, Vol. 5, No. 2, pp. 299-314.

Wagstaff, A., \& Lindelow, M., 2008, Can Insurance Increase Financial Risk? The Curious Case of Health Insurance in China, Journal of Health Economics, Vol. 27, No. 4, pp. 990-1005.

Wagstaff, A., \& Yu, S., 2007, Do Health Sector Reforms Have Their Intended Impacts? The World Bank's Health VIII Project in Gansu Province, China., Journal of Health Economics, Vol. 26, No. 3, pp. 505-35.

Wagstaff, A., Bilger, M., Sajaia, Z., \& Lokshin, M., 2011, Health Equity and Financial Protection: Streamlined Analysis with ADePT Software (Washington: World Bank).

Wagstaff, A., Lindelow, M., Jun, G., Ling, X., \& Juncheng, Q., 2009, Extending Health Insurance to the Rural Population: An Impact Evaluation of China's New Cooperative Medical Scheme, Journal of Health Economics, Vol. 28, No. 1, pp.1-19.

Woldemichael, A., \& Shimeles, A., 2015, Measuring the Impact of Micro-Health Insurance on Healthcare Utilization: A Bayesian Potential Outcomes Approach. African Development Bank Group Working Paper Series Nº 225. 
Yilma, Z., Mebratie, A., Sparrow, R., Dekker, M., Alemu, G., \& Bedi, A. S., 2015, Impact of Ethiopia's Community-Based Health Insurance on Household Economic Welfare, World Bank Economic Review.

Yip, W., \& Hsiao, W. C., 2009, Non-evidence-based Policy: How Effective Is China's New Cooperative Medical Scheme In Reducing Medical Impoverishment? Social Science \& Medicine, Vol. 68, No. 2, pp. 201-209.

Yip, W., \& Berman, P., 2001, Targeted Health Insurance in a Low-Income Country and Its Impact on Access and Equity in Access: Egypt's School Health Insurance, Health Economics, Vol. 10, No. 3, pp. 207-20. 